ISSN: 0213-2079

DOI: http://dx.doi.org/10.14201/shhmo2013356198

\title{
ASIENTOS Y ASENTISTAS MILITARES EN EL SIGLO XVII: EL EJEMPLO DEL PAN Y LA PÓLVORA"
}

\section{Asientos and Military Contractors in the Seventeenth Century: The Example of the Bread and the Gunpowder}

\author{
Antonio José RODRÍGUEZ HERNÁNDEZ
}

UNED

Correo-e: ajrodriguez@geo.uned.es

RESUMEN: En este texto abordaremos la importancia de los asientos dentro del gasto de los ejércitos que lucharon en España durante el siglo XVII. Para ello analizaremos la gestión del suministro de pan de munición, cuya cuantía era la partida de gasto más relevante de cualquier ejército, la cual siempre estuvo en manos privadas. También estudiaremos la fabricación de pólvora en España, y su paso a manos privadas bajo asientos generales basados en un monopolio sujeto a un estanco.

Palabras clave: Asientos, Suministro, Pan de munición, Pólvora y Ejército.

ABSTRACT: This text approaches the importance of the Asientos inside the expense of the armies that fought in Spain during the 17th century. For it we analyze the management of the supply of bread whose quantity was the most outstanding expense of any army, which was always in private hands. We also analyze the production of gunpowder in Spain, and their transformation in a monopoly in private hands in the form of Asientos Generales.

Key words: Asientos, Supply, Bread, Gunpowder and Army.

Este trabajo ha sido realizado gracias a la ayuda de los proyectos financiados por el Ministerio de Economía y Competitividad: Comercio y Finanzas Internacionales en una España en Transición, 1680-1721 (HAR2011-25907) y Conservación de la Monarquía y Equilibrio Europeo entre los siglos XVII y XVIII (HAR2012-37560-C02-01). 
Desde hace décadas, tras la aparición de la magnífica monografía del profesor Thompson ${ }^{1}$, se ha establecido un importante debate en torno a la importancia y significado de los asientos militares, y si estos supusieron una abrogación de soberanía que afectó a la misma naturaleza del Estado. Se ha debatido que -en el caso de España- pudo ser un paso hacia atrás en la construcción del Estado Moderno, que según la teoría Weberiana se había construido sobre el pilar de la monopolización del uso de la violencia y el ejercicio de la guerra, controlando y regulando todos los recursos que tenían que ver con ella (como las armas, municiones, construcción naval, el reclutamiento...).

A día de hoy esta visión peyorativa de los asientos está en tela de juicio, ya que no se ha podido demostrar que los ejércitos y armadas proveídos por asiento estuvieran peor alimentados o armados, ni que esto influyera en su capacidad de combate $^{2}$. La monarquía de los Austrias se vio obligada ante la falta de liquidez, la malversación y la poca integridad de algunos ministros a imponer sistemas de aprovisionamiento privado, que incluso estaban mejor controlados que los que se administraban directamente, algo que lógicamente no evitó los problemas o fraudes, aunque sí permitió cierto ahorro y una mayor adecuación y previsión del gasto $^{3}$. De hecho, la mayor parte de los estados europeos optaron por establecer contratos privados de provisión. Pero, a diferencia de España, en muchos de ellos no se habían dado los pasos para establecer una administración militar centralizada, algo bastante evidente en el caso del reclutamiento, al ser la monarquía uno de los pocos estados que mantuvo un sistema de reclutamiento centralizado y controlado directamente por la administración ${ }^{4}$. En este sentido era lógico que para España el cambio supusiera una marcha atrás, algo que no ocurrió en muchos países en donde los sistemas de reclutamiento y suministro estuvieron siempre en manos privadas.

En las siguientes páginas, tras abordar la importancia de los asientos dentro del gasto de los ejércitos establecidos durante la segunda mitad del siglo XvII en la península, analizaremos la gestión del suministro de pan de munición, que suponía el tanteo más voluminoso del gasto real de un ejército, que si bien estuvo en manos privadas -beneficiándose de él muchos negociantes-, para nada suponía

1. Thompson, I. A. A.: Guerra y decadencia: gobierno y administración en la España de los Austrias, 1560-1620. Barcelona, 1981.

2. Goodman, D.: El poderío naval español. Historia de la Armada española del siglo XVII. Barcelona, 2001.

3. Esteban Estríngana, A.: «Administración militar y negocio de guerra en los Países Bajos católicos (siglo XVII)», en Herrero Sánchez, M. y Crespo Solana, A. (coords.): España y las 17 provincias de los Países Bajos: una revisión historiográfica (XVI-XVIII). vol. I, Córdoba, 2002, pp. $65-100$.

4. Tallet, F.: War and Society in Early Modern Europe 1495-1715. Routledge, 1992, p. 73. 
una pérdida de soberanía por parte del Estado. Otro elemento que analizaremos será el suministro de pólvora, que a lo largo del siglo XviI estuvo sujeto a asientos generales que suponían un monopolio y un estanco, por el cual la monarquía y las Cortes perdían autoridad y soberanía a favor de unos precios moderados para uso militar, lo cual en muchos casos condujo al fraude y al desabastecimiento.

\section{Gasto y asientos}

Lo primero que debemos preguntarnos cuando hablamos de asientos es su extensión e importancia, para lo cual es necesario conocer el gasto, especialmente el originado a raíz de las nuevas necesidades militares surgidas después de $1640^{5}$. El análisis de las provisiones generales de la monarquía en un año concreto nos da una amplia perspectiva de la importancia del gasto militar, que se acercaba al $90 \%$ del total, empleándose lo restante en el mantenimiento de la Casa Real, la diplomacia, pensiones y otros gastos menores. A la altura de 1663 la monarquía no disponía de los suficientes fondos -como venía siendo habitual ${ }^{6}$-, haciendo referencia el informe consultado a las cantidades que podrían excusarse. De esta manera, casi una tercera parte de lo que se pensaba gastar no fue atendido, en especial los gastos que tenían lugar fuera de la península relativos al mantenimiento de ejército de Flandes o las embajadas exteriores, dándose prioridad a la guerra con Portugal.

Tabla I. Provisiones Generales de toda la monarquía para 1663

\begin{tabular}{|l|r|r|c|}
\hline & \multicolumn{1}{|c|}{ Iniciales } & Tras la rebaja & Reducción \\
\hline Provisiones para fuera de España $^{1}$ & 3.743 .740 & 1.999 .088 & $47 \%$ \\
\hline Embajadas & 327.854 & 104.096 & $68 \%$ \\
\hline Ejército de Extremadura & 8.401 .772 & 5.732 .304 & $32 \%$ \\
\hline Ejército de Galicia & 1.867 .368 & 1.411 .768 & $24 \%$ \\
\hline Ejército Frontera de Castilla & 428.000 & 268.000 & $37 \%$ \\
\hline Armada Real & 2.056 .434 & 1.256 .434 & $39 \%$ \\
\hline Presidios $^{2}$ & 1.339 .575 & 1.339 .575 & $0 \%$ \\
\hline Pagas a portugueses y catalanes & 104.000 & 104.000 & $0 \%$ \\
\hline
\end{tabular}

5. Rodríguez Hernández, A. J: «Los primeros ejércitos peninsulares y su influencia en la formación del Estado Moderno durante el siglo XvII» en González EncIso, A. (ed.): Un Estado Militar. España, 1650-1820. Madrid, 2012, pp. 19-64.

6. En 1655 los ingresos de las rentas reales ascendía a 12.471 .579 ducados, y en 1666 a 17.215.432 en Andrés Ucendo, J. I. y Lanza García, R.: «Estructura y Evolución de los ingresos de la Real Hacienda de Castilla en el siglo XvII», Studia Historica. Historia Moderna 30 (2008), pp. 147-190. 


\begin{tabular}{|l|r|r|c|}
\hline Mina de Almadén & 150.000 & 150.000 & $0 \%$ \\
\hline Casas Reales & 1.008 .200 & 1.008 .200 & $0 \%$ \\
\hline Provisiones ordinarias en la Corte & 500.000 & 500.000 & $0 \%$ \\
\hline Provisiones en diferentes partes & 221.164 & 84.104 & $62 \%$ \\
\hline Costes de adehalas e intereses (10\%) & 2.014 .810 & 1.395 .757 & $31 \%$ \\
\hline TOTAL: & 22.162 .917 & 15.353 .326 & $31 \%$ \\
\hline
\end{tabular}

Fuente: Archivo General de Simancas [en adelante AGS], Guerra Antigua [en adelante GA], leg. 2.026. (Notas: [1] Fundamentalmente al ejército de Flandes y a pagos a diferentes aliados. [2] Todo a través de un asiento. [3] La mayoría fondos destinados al reclutamiento de tropas).

Gracias a estos datos contables podemos comprobar la importancia de los asientos y del sistema de provisión privado. De hecho, si tenemos en cuenta los gastos de los ejércitos que combatían en la península, los presidios y la Armada, nos damos cuenta de que la mayor parte de los fondos facilitados procedían de asientos ajustados para la provisión de dinero o se suministraban para afrontar el pago de los contratos privados de suministro. El análisis de los gastos de cada ejército -en especial los de Extremadura, Galicia y la frontera de Castilla-, nos indica que aunque la provisión en metálico a los ejércitos podía suponer entre el $46 \%$ y más del $50 \%$ del total de los fondos, estos se usaban fundamentalmente para hacer frente a las pagas de los oficiales y la tropa, aunque también para toda una serie de gastos menores. Esta partida era la primera que solían ser «recortada» cuando no había suficiente para atender todas las necesidades, pasando esta remesa a ser entre el 20 y el $30 \%$ del gasto real. En cambio otras partidas no solían sufrir excesivos recortes al reconocerse que su suministro era más esencial para llevar a cabo la guerra, como los fondos relativos al suministro de pan y forrajes (más de $1 / 3$ parte del gasto real del ejército), caballos (entre el 5 y $10 \%$ ), armas y municiones (un 5\% aproximadamente), o carruajes (entorno al 15\% del gasto). Ante su debilidad administrativa y financiera, la Corona en muchos casos se veía obligada a firmar asientos que aseguraban servicios esenciales a las tropas en detrimento de sus pagas. Dentro de estos servicios el más representativo es el del pan de munición. 
ANTONIO JOSÉ RODRÍGUEZ HERNÁNDEZ

TABLA II. Provisiones para los diferentes ejércitos, 1663

\begin{tabular}{|c|c|c|c|}
\hline Extremadura & Previsto & Tras la rebaja & Reducción \\
\hline Pagas & 3.874 .358 & 1.701 .000 & $56 \%$ \\
\hline Pan y forrajes & 2.167 .510 & 1.999 .510 & $8 \%$ \\
\hline Artillería, armas y municiones & 335.758 & 335.758 & $0 \%$ \\
\hline Carruaje & 920.000 & 677.740 & $26 \%$ \\
\hline Remonta de la Caballería & 312.000 & 312.000 & $0 \%$ \\
\hline Vestuario & 83.400 & 30.000 & $64 \%$ \\
\hline Camas, mantas y sillas de montar & 47.330 & 14.880 & $69 \%$ \\
\hline Levas y apresto de milicias & 661.416 & 661.416 & $0 \%$ \\
\hline TOTAL: & 8.401 .772 & 5.732 .304 & $32 \%$ \\
\hline Galicia & Previsto & Tras la rebaja & Reducción \\
\hline Pagas & 855.600 & 400.000 & $53 \%$ \\
\hline Pan y forrajes & 540.000 & 540.000 & $0 \%$ \\
\hline Artillería, armas y municiones & 65.744 & 65.744 & $0 \%$ \\
\hline Carruaje & 250.000 & 250.000 & $0 \%$ \\
\hline Remonta de la Caballería & 120.000 & 120.000 & $0 \%$ \\
\hline Compra de jergones & 12.000 & 12.000 & $0 \%$ \\
\hline Apresto de fragatas & 24.024 & 24.024 & $0 \%$ \\
\hline TOTAL: & 1.867 .368 & 1.411 .768 & $24 \%$ \\
\hline Frontera de Castilla & Previsto & Tras la rebaja & Reducción \\
\hline Pagas & 240.000 & 80.000 & $67 \%$ \\
\hline Pan y forrajes & 140.000 & 140.000 & $0 \%$ \\
\hline Remonta de la Caballería & 48.000 & 48.000 & $0 \%$ \\
\hline TOTAL: & 428.000 & 268.000 & $37 \%$ \\
\hline
\end{tabular}

Fuente: AGS, GA, leg. 2.026. 


\section{UN EJÉRCITO MARCHA SOBRE SU ESTÓMAGO}

Esta máxima de Napoleón resume muy bien el principal problema logístico que tenía cualquier ejército ${ }^{7}$. Alimentar y alojar un ejército era un problema difícil de solucionar que requería procedimientos organizativos complicados que demandaban una estructura estatal avanzada ${ }^{8}$. En casi toda Europa la administración militar recurrió a empresarios particulares ${ }^{9}$, a través de los asientos, para proveer mejor a sus soldados, buscando así flexibilidad y ahorro, además de no tener que crear una administración burocrática permanente y duradera, elemento que a fin de cuentas tardaría varios siglos más en desarrollarse por completo y satisfactoriamente.

El problema de fondo era la falta de dinero, por lo que en múltiples ocasiones los soldados no cobraban sus pagas. Este era un mal difícil de solucionar, pero que todos los ejércitos padecían ${ }^{10}$. A comienzos de 1658 el ejército de Extremadura estaba en un estado miserable, ya que la tropa había cobrado 3 pagas enteras en 16 meses, por lo que los soldados debían subsistir gracias al pan de munición ${ }^{11}$. Los ejércitos recibían dinero, pero cuando este no era suficiente solía emplearse en pagar la provisión de todo tipo de géneros y municiones, como el pan, los forrajes y caballos, la artillería, las fortificaciones, los hospitales... y en última instancia -y si había fondos suficientes-, en socorrer económicamente a las tropas. Pese a todo, lo normal es que las tropas pudieran cobrar algunas pagas, especialmente al comienzo de la campaña militar y al finalizar esta, pero no siempre en un año cobraban más de 3 a 5 pagas enteras, ya que muchas veces los pagos se fraccionaban, cobrando los militares entre la mitad y una cuarta parte de su sueldo ${ }^{12}$. En regiones como Galicia incluso se reconocía que se podría mantener el ejército con tan solo 6 medias pagas anuales, además del pan, ante la colaboración del reino y debido a que los soldados eran semiprofesionales ${ }^{13}$.

7. Van Creveld, M.: Supplying War. Logistics from Wallenstein to Patton. Cambridge, 1977.

8. Parker, G.: El ejército de Flandes y el Camino Español 1567-1659. Madrid, 1991, pp. 126-129. Tilly, C.: Coercion, Capital and European States: AD 990-1992. Cambridge, 1990, p. 84 y ss.

9. Hale, J. R.: Guerra y sociedad en la Europa del Renacimiento, 1450-1620. Madrid, 1990, pp. 204-205.

10. Van Nimwegen, O.: The Dutch Army and the Military Revolutions 1588-1688. Boydell, 2010.

11. Carta del Veedor General del ejército de Extremadura, 15 de febrero 1658. AGS, GA, leg. 1.911.

12. Relación jurada de Bartolomé Rodríguez de Andrade, Pagador General del ejército de Extremadura, 1664-1671. AGS, Contaduría Mayor de Cuentas $3^{a}$ época [en adelante CMC3], leg. 1.435 .

13. Copia del papel de Diego Sarmiento a Luis de Oyanguren, Madrid, 8 de noviembre 1662. AGS, GA, leg. 2.083. 
El pan de munición por sí solo no era suficiente para mantener a los soldados ${ }^{14}$, pero las deserciones masivas se producían cuando a la falta de pagas se le unía la falta de pan, algo que siempre se trató de evitar. Entonces no solo los soldados huían arrastrados por la necesidad, sino también los oficiales veteranos. En septiembre de 1667 el ejército de Extremadura se vio reducido ante las deserciones por la conjunción fatal de estos dos factores ${ }^{15}$. La dantesca situación en algunos frentes, en donde no se cobraba puntualmente, hacía que muchos soldados huyeran nada más llegar, al ver la miseria que se padecía, la cual solía cebarse especialmente sobre los bisoños ${ }^{16}$.

\section{El PAN DE MUNICIÓN EN ESPAÑA: PRESIDIOS Y EJÉRCITOS}

Con el tiempo, el suministro constante de pan se hizo uno de los mayores problemas a los que un general de la Época Moderna debía hacer frente. El aumento de los ejércitos no siempre hizo que estos estuvieran bien pagados ni abastecidos. Desde finales del siglo xvi los gobiernos fueron conscientes de que suministrar directamente a la tropa el alimento básico, el $\operatorname{~pan~}^{17}$, evitaba problemas y deserciones, ya que no siempre las pagas llegaban a tiempo ni los vivanderos o comerciantes locales tenían géneros suficientes, o a unos precios aceptables. El suministro a cargo de los gobiernos incrementaba los gastos directos, pero aseguraba la subsistencia de la tropa. Para hacer frente a este nuevo compromiso se acudió a los asentistas, que a un precio bastante ajustado y competitivo se comprometían a suministrar todo el pan necesario por al menos un año en un frente bélico concreto. La competencia entre asentistas, las pujas, y el adelanto de las operaciones permitían que el gobierno pudiera conseguir unos precios más bajos y uniformes, independientemente de la distancia o la época del año.

Si bien este sistema se impuso desde la década de 1590 en Flandes -el principal campo de batalla de la monarquía-, en las primeras décadas del siglo xvir no existía en la península o Nápoles ${ }^{18}$. En territorio peninsular no hubo necesidad de formar

14. "Se deshace la gente por no poder ser socorrida en País tan mísero como es este [Extremadura], donde no tiene el soldado otro recurso que el del pan de munición para mantenerse». Carta de Don Juan de Austria, Badajoz, 19 de abril 1664. AGS, GA, leg. 2.054.

15. Cartas del Marqués de Caracena, Badajoz, 10, 11, 12 y 14 de septiembre 1667. AGS, GA, leg. 2.136.

16. Carta del Marqués de Viana, Pontevedra, 4 de junio 1661. AGS, GA, leg. 1.958.

17. Henríquez De Villegas, D.: Levas de gente de guerra: su empleo en todas las facciones militares... Madrid, 1647, p. 47. Sala y Abarca, F. V.: Después de Dios la Primera obligación y glosa de órdenes militares. Nápoles, 1681, p. 281.

18. Parker, G.: El ejército de Flandes..., pp. 205-207. Esteban Estríngana, A.: «La Ejecución del Gasto Militar y la Gestión de los Suministros. El abastecimiento de pan de munición en el ejército de Flandes durante la primera mitad del siglo XviI» en Rizzo M. et al. (eds.): Le Forze del Principe. 
un ejército de campaña, y en los Presidios -en donde se concentraban la mayor parte de las tropas que defendían la península, sus costas y los pasos pirenaicos-, no se había establecido el suministro de pan ${ }^{19}$. A mediados de la década de 1630 las nuevas necesidades defensivas y el incremento de sus dotaciones sacaron a la luz la necesidad de proveer este medio esencial también en estas guarniciones fijas. En 1635, gracias a una leva generalizada en toda Castilla, las dotaciones de los presidios estaban muy cerca de estar al completo $^{20}$. Para reforzar Cádiz llegaron miles de reclutas apercibidos en toda Andalucía, colapsando las pobres infraestructuras que debían acogerles. En esos momentos un pan de dos libras de peso costaba en Cádiz 36 maravedíes, cobrando los soldados mensualmente 8 reales, lo que significaba que no les llegaba para comer todos los días, problema al que se sumaba que no tenían cama para dormir, ni un suelo bajo techo en el que refugiarse. Tal precariedad, y la facilidad para fugarse, habían hecho que 1.821 soldados de los 2.245 llegados en los últimos dos años hubieran desaparecido ${ }^{21}$. Para que la infantería pudiese subsistir se ordenó que a cada soldado raso se le diese un real de socorro y pan de munición al día, lo que al menos aseguraría su sustento. Mientras tanto, los nuevos reclutas se alimentarían a cargo de las raciones contratadas por la Armada para los embarcados, asiento que desde hacía años se ajustaba $^{22}$. La exigüidad de las pagas también se extendía a la Armada. En 1636 la Junta de Armadas reconocía que, aunque ese año se pudieran dar 6 pagas, la marinería no se podría mantener en Lisboa ante los subidos precios del pan, por lo que, si se quería conservar a las tripulaciones para salir a la mar al año siguiente, se les debería suministrar bizcocho ${ }^{23}$.

El incremento de los socorros diarios que recibían los soldados -forma de pago más coherente, ya que se pagaba en mano y evitaba los fraudes- no era suficiente. Un nuevo informe llegado desde Cádiz en 1637 aseveraba que, aunque las tropas recibían 2 reales de socorro diario, esto no bastaba para comer, ya que una libra

Recursos, Instrumentos y Limites en la Práctica del Poder Soberano en los Territorios de la Monarquía Hispánica. Murcia, 2003, vol. I, pp. 409-468.

19. Contreras Gay, J.: «Consideraciones generales sobre la defensa de la Península entre 1580 y 1640» en El Mediterráneo: hechos de relevancia histórico-militar y sus repercusiones en España, (Sevilla, 9-12 de mayo de 1995): V Jornadas Nacionales de Historia Militar. Sevilla, 1998, pp. 647-664.

20. Rodríguez Hernández, A. J.: «Las Cortes de Castilla y la leva para los Presidios: La gestión de la primera recluta obligatoria de los Austrias» en Pérez Álvarez, M. J., Rubio Pérez, L. M., Martín García, A. (eds.): Campo y campesinos en la España Moderna. Culturas políticas en el mundo hispano. León, 2012, pp. 1731-1744.

21. Carta de Juan de Castro y Castilla, Cádiz, 12 de agosto 1635. Consultas del Consejo de Guerra, 2 septiembre y 28 de noviembre 1635. AGS, GA, leg. 1.121. Carta de Juan de Castro y Castilla, Cádiz, 5 de agosto 1635. AGS, GA, leg. 1.147.

22. Orden al Marqués de Monesterio, Madrid, 23 de octubre 1635. Consulta del Consejo de Guerra, 2 de diciembre 1635. AGS, GA, leg. 1.123.

23. Junta de Armadas, 18 de abril 1636. AGS, GA, leg. 3.167. 
de pan valía 24 maravedíes y una de carne 2 reales, por lo que muchos estaban enfermando ${ }^{24}$. Sin duda el mal endémico de los Presidios y guarniciones fijas fue que por norma general nunca contaron con el suficiente dinero para su mantenimiento, a pesar de que para ello se ajustaron numerosos asientos. Su situación fue en muchos momentos crítica, ante la continua falta de fondos para hacer frente a los gastos periódicos como el mantenimiento de los hombres, fortificaciones, pertrechos y municiones, algo que no solía ocurrir en el resto de los ámbitos territoriales de la monarquía ${ }^{25}$.

La falta de consignaciones hizo que las guarniciones de los presidios padecieran unos retrasos crónicos en sus pagas ${ }^{26}$. En 1651 se intentó fijar la consignación para los presidios guipuzcoanos, para que a cada soldado se le pudiera pagar un real de vellón al día como socorro, además de comprar trigo, para poder proveer diariamente a los soldados pan de munición como se hacía en los ejércitos de campaña, ya que se creía que esto sería suficiente para que los soldados se mantuviesen ${ }^{27}$. Las cosas empeoraron con el tiempo, ya que no siempre se podía remitir dinero ante los continuos enfrentamientos bélicos que no daban tregua a la Hacienda, de ahí las continuas deserciones. En 1661 la situación había llegado a tal punto que el gobernador de los presidios guipuzcoanos afirmaba que durante los 7 años que llevaba en el cargo solo habían recibido 9 pagas ${ }^{28}$. El problema distaría bastante de estar solucionado a corto plazo. En 1677 las cosas no habían cambiado, y los presidios estaban casi indefensos, al estar los soldados «muertos de necesidad», ya que lo único que recibían era pan $^{29}$. Situación que prosiguió ${ }^{30}$, por lo que en 1687, ante la falta de pan, los soldados se vieron obligados a pedir limosna en las iglesias ${ }^{31}$.

En muchas guarniciones peninsulares se terminó por establecer asientos de suministro de pan para que al menos parte del escaso dinero llegado se empleara en mantener a los soldados ${ }^{32}$. Pero la penuria continuó ante la falta de fondos. En abril de 1679 se daba cuenta de que hacía 23 meses que no se suministraba a

24. Carta de Juan de Velasco, Cádiz, 5 de mayo 1637. AGS, GA, leg. 1.202.

25. Carta del Marqués de Canzano, Gobernador de los presidios de Guipúzcoa, 26 de diciembre 1684. Consulta del Consejo de Guerra, 29 de enero 1685. AGS, GA, legs. 2.640 y 2.650.

26. Junta de Guerra de España, 16 de septiembre y 1 de octubre 1647. AGS, GA, leg. 1.644.

27. Carta del Consejo de Guerra para el Barón de Bateville, Capitán General de la provincia de Guipúzcoa, 12 de septiembre 1654. AGS, GA, libro 245, fol. 42.

28. Consulta del Consejo de Guerra, 21 de septiembre 1661. AGS, GA, leg. 1.995.

29. Carta de don Luis de Ferrer, Gobernador de Fuenterrabía, 25 de abril 1677. AGS, GA, leg. 2.399 .

30. Consulta del Consejo de Guerra, 7 de septiembre 1678. AGS, GA, leg. 2.413.

31. Consulta del Consejo de Guerra, 11 de agosto 1687. AGS, GA, leg. 2.725.

32. Orden al Marqués de la Laguna, 28 de enero 1669. Asiento del pan de munición de Gibraltar, 20 de septiembre 1672. AGS, GA, libro 304, fols. 83v, 316 y 135v. 
la guarnición de La Coruña ni socorro ni pan. Muchos eran viejos e impedidos, inútiles para el servicio, que debían pedir limosna para poder alimentarse, por lo que hacían cola en los conventos para pedir sopa, ya que previamente se habían visto obligados a vender sus armas, ejerciendo muchos como sastres o zapateros ${ }^{33}$. No es de extrañar que meses después los soldados saquearan en el puerto dos chalupas cargadas de trigo, ya que llevaban 30 meses sin cobrar ${ }^{34}$.

El desarrollo de las operaciones militares contra los franceses en la frontera catalana motivaría el ajuste de los primeros asientos de pan para el ejército de campaña, ya que se reconocía que era necesario para que el ejército «saliera a campear» ${ }^{35}$. Con ello lógicamente se evitaría que las tropas se dedicaran a forrajear y a obtener medios a costa de la población. En cambio, en otras zonas el inició de esta práctica tardó en aparecer. El ejército que combatía en la frontera gallega estaba compuesto en su mayor parte por naturales alistados para la ocasión, por lo que hasta 1642 vivían directamente de la población ${ }^{36}$, lo que estaba causando notables contratiempos. Finalmente se debió concertar un asiento de pan con varios proveedores, que a razón de 14 maravedíes entregaban un pan de centeno de libra y media de peso, tanto en los cuarteles de Monterrey como en los de Tuy y la ribera del Miño. El precio era el mismo independientemente de las tres variables que modificaban su valor -como el lugar de entrega, la estación o las oscilaciones del precio según las fluctuaciones de las cosechas-, lo cual suponía un claro ahorro, asegurándose de antemano el gobierno el suministro y el precio ${ }^{37}$.

\section{El ejemplo de Galicia}

Los asientos solían sufragarse gracias a los impuestos cobrados localmente, por lo que con el tiempo fue lógico que este tipo de contratos atrajeran a personas relacionadas con su recaudación. En Galicia fue el caso de Juan de Urrea, empresario que mantuvo una amplia trayectoria, y que tras conseguir en $1651 \mathrm{el}$ arriendo por diez años de las Alcabalas y dos primeros porcientos de Galicia ${ }^{38}$,

33. Carta del Marqués de Villafiel, Gobernador de Galicia, Vigo, 28 de abril 1679. AGS, GA, leg. 2.472.

34. Carta del Marqués de Villafiel, La Coruña, 1 de octubre 1679. AGS, GA, leg. 2.472.

35. Junta de Ejecución, 14 de junio 1639. AGS, GA, leg. 1.256.

36. Eiras Roel, A.: «Las Juntas del reino de Galicia de 1642 a 1647» en Actas de las Juntas del Reino de Galicia, vol. V: 1642-1647. Santiago de Compostela, 1995, p. 6 y ss.

37. Cuenta de las provisiones del ejército de Galicia, 1647-1653. Cuentas de Esteban Fernández de Barbeito, pagador del reino de Galicia, 1645-1652. AGS, CMC3, legs. 5 y 1.375.

38. Eiras Roel, A.: «Las Juntas del Reino de Galicia y la política fiscal de 1655 a 1665 » en Actas de las Juntas del Reino de Galicia, Vol. VII: 1655-1665. Santiago de Compostela, 1999, p. 46. Cuentas de Juan de Urrea, de sus asientos sobre alcabalas y unos por ciento de Galicia, 1651-1662. AGS, CMC3, leg. 2.732, fol. 15. 
se comprometió en 1657 a suministrar el pan de munición a las tropas y la cebada para los caballos por el método de factoría, aunque nunca antes se había encargado de ello o tenía experiencia en la materia ${ }^{39}$. Lo cierto es que la iniciativa de este asiento surgía del propio Consejo de Guerra, que en un momento de estrechez necesitaba con urgencia un empresario con capacidad económica. Con este se pactaría una rebaja en las consignaciones entregadas, que ascenderían a 173 millones de maravedíes en tres años, a pesar de que el asiento correría por dos, ya que durante el primer año había pocas rentas locales desembarazadas, rebajándose estas en relación al anterior asiento en al menos 10 millones. A cambio debía suministrar anualmente 240.000 escudos al año, 100.000 de ellos en pan y cebada, y el resto en dinero en metálico. El negocio era importante, por lo que el Consejo de Guerra, azuzado por el gobernador de Galicia y las necesidades bélicas, medió ante el de Hacienda para que este accediera a parte de las condiciones de Urrea. Este también llegó a pedir un puesto con sueldo y emolumentos en el Tribunal Mayor de Cuentas, condición que no fue concedida ante la negativa del Consejo de Hacienda, que esperaba que si se accedía a esto se abriría demasiado la puerta al resto de los asentistas ${ }^{40}$.

La diferencia de los factores con respecto a los asentistas, era que los primeros trabajaban por cuenta de la Real Hacienda y no cobraban los intereses al no asumir ningún riesgo, al recibir alguna consignación fija situada en las rentas, aunque el factor debía adelantar grandes sumas de dinero debido a que la recaudación de impuestos se podía retrasar ${ }^{41}$. Que no cobrara los mismos intereses no significó que Urrea no quisiera beneficiarse o sacar provecho económico. En enero de 1658 se avisaba de que Urrea debía cierta cantidad de pan, ya que no había podido suministrar todo lo concertado, además de que se estaban observando muchas irregularidades en la calidad del pan suministrado ${ }^{42}$. En pocas semanas el ejército realizó una inspección, enviando a Madrid 8 panes de los entregados. Su examen indicó que alguno estaba incluso hueco por dentro, y que la mayoría estaban hechos con trigo dañado y de mala calidad, por lo que las harinas estaban endurecidas, pasadas y en algunos casos corrompidas, al haberse almacenado trigo en lonjas húmedas. Curiosamente el pan de centeno suministrado era de mejor

39. Relación de todo el pan, cebada y dinero que el Proveedor General Juan de Urrea ha proveído..., 1657-58. AGS, GA, leg. 1.929. Título de proveedor general del ejército de Galicia a Juan de Urrea, Madrid, 18 de marzo 1657. AGS, GA, libro 256, fol. 98.

40. Consulta del Consejo de Guerra, 23 de enero 1657. Carta del Presidente de Hacienda, 7 de enero 1657. Memorial de Juan de Urrea. Postura de Francisco de Castilla de la Concha, Madrid, 14 de julio 1656. AGS, GA, leg. 1.913. Cuentas de Juan de Urrea sobre la provisión del ejército de Galicia, 1657-58. AGS, CMC3, leg. 2.278, fol. 9.

41. Sanz Ayán, C.: Los Banqueros de Carlos II. Valladolid, 1989, pp. 35-37.

42. Carta de Vicente Gonzaga, Pontevedra, 25 de enero 1658. AGS, GA, leg. 1.929. 
calidad, especialmente si se comparaba con el de trigo ${ }^{43}$. A pesar del fragrante fraude, Urrea siguió suministrando el pan y la cebada al ejército durante el resto del año, ya que la campaña militar no podía detenerse, llegando a proveer 10.000 raciones de pan al día, alegando el propio asentista que seguía «teniendo en primer lugar el servicio de su magestad» ${ }^{44}$. Las posteriores indagaciones del Consejo de Hacienda incidieron en los abusos de este y de sus métodos para enriquecerse, como el uso de harina inferior, la falta de peso de las raciones proporcionadas o el hecho de no pagar el transporte de la leña que los vecinos de la zona debían suministrar para sus hornos ${ }^{45}$.

Juan de Urrea perdió el contrato de provisión de pan, lo que no le apeó del resto de negocios que mantenía con la administración, ya que años después se encargaría de proveer la plaza de Ceuta durante casi una década, no sin importantes problemas e incumplimientos ${ }^{46}$. A pesar del fraude, debemos alegar, para descargo del asentista, que ciertamente la misión que se le encomendó fue complicada, ya que debió asumir unas funciones en un momento en el que el ejército de Galicia duplicó sus fuerzas y prolongó sus actividades bélicas más allá de la tradicional campaña estival, siendo las campañas de 1657 y 1658 las primeras propiamente ofensivas que realizaba. Durante estos dos años el asentista fue capaz de entregar 5.624.573 raciones de pan a un precio algo inferior al de otros años, a 13 maravedíes de vellón ${ }^{47}$. Sus sustitutos tuvieron problemas para cumplir el asiento debido a la falta de dinero, ya que estos no eran arrendadores de rentas. Al no poder comprar por adelantado harinas en la primavera, su provisión empeoró durante el fin del verano y el otoño. Pese a todo continuaron suministrando pan, sin faltar un solo día, ajustándose a la calidad, a pesar de que algunos comerciantes locales no les vendían granos y que buena parte de las consignaciones suministradas no estaban desembarazadas ${ }^{48}$. Ante los problemas de los nuevos asentistas, que solo llevaban 4 meses en ello, Juan de Urrea no tardó en intentar recuperar su negocio, ya que de hecho él era uno de los causantes de la presión a la que se veían sometidos los nuevos titulares. En 1661 pujó para hacerse con la provisión, bajando en dos maravedíes cada ración de pan, aunque los asentistas locales representados por Fernando

43. Informe de Diego de Novoa, Pontevedra, 15 de febrero 1658. Testimonio de los panes llegados al Consejo de Hacienda, 1 de abril 1658. AGS, GA, leg. 1.929.

44. Carta de Juan de Urrea, Fuerte de San Luis Gonzaga, 3 de septiembre 1658. AGS, GA, leg. 1.929.

45. SAnz Ayán, C.: Los Banqueros..., p. 402.

46. Rodríguez Hernández, A. J.: La ciudad y la guarnición de Ceuta (1640-1700). Ejército, fidelidad e integración de una ciudad portuguesa en la Monarquía Hispánica. Ceuta, 2011, pp. 110-115.

47. Cuentas sobre la provisión del pan de munición en Galicia durante 1657-58. AGS, CMC, $3^{a}$ época leg. 3.403 , fol. 1.

48. Carta de Pedro de Robles, Pontevedra, 21 de mayo 1661. AGS, GA, leg. 1.929. 
Rodríguez Lorenzana asumieron dicho reajuste, modificando sus márgenes, lo que significó un mayor beneficio para la Hacienda ${ }^{49}$.

La bajada del precio y la poca entidad de los asentistas terminaron por apearles del negocio, ya que no tenían medios al ser unos mayoristas locales, siendo sustituidos en 1662 por un gran asentista con una dilatada experiencia en el suministro de granos, Pedro Aguerri. Este había despuntado desde hacía más de una década como negociante, centrándose especialmente en el suministro de granos y dinero para el ejército de Cataluña, no dejando de lado la provisión de carruajes o cualquier otra cosa que necesitara la monarquía ${ }^{50}$. Provisiones que llevó con bastante éxito, habida cuenta de su habilidad negociadora con los comerciantes locales y que las cláusulas de sus contratos le permitían el traslado de grano de un lugar a otro sin tener que hacer frente a pagos innecesarios, pudiendo evitar embargos y prohibiciones ${ }^{51}$. A esas alturas su negocio de provisión se había reducido mucho ante la paz con Francia, por lo que sin dudarlo buscó un nuevo mercado para sus asientos en Galicia, a pesar de que allí no disponía de las infraestructuras necesarias. Al contrario que lo ocurrido durante los años anteriores, el asiento de la casa Aguerri era mucho más ambicioso y complementario, ya que además de comprometerse a proveer 6.726.000 raciones de pan para la campaña de 1663 -a razón de 17 maravedíes-, y 90.000 fanegas de cebada para la caballería a 15 reales de vellón, también se obligaba a suministrar dinero y los carruajes necesarios ${ }^{52}$. En total sus consignaciones ascendían a 1.390 .000 escudos de vellón, el $74 \%$ de los gastos teóricos asignados al ejército de Galicia ${ }^{53}$.

A pesar del volumen del negocio, Aguerri tuvo problemas para cumplir debido las condiciones dadas y al adelanto impuesto para que en el ejército hubiera 100.000 raciones de pan de reserva y otras 200.000 de cebada, debiendo adelantar mucho la molienda para poder tener la suficiente harina antes de empezar la campaña. Si bien el asentista pudo agilizar la compra de grano para intentar cumplir con su obligación, la demora del trigo que debía llegar de Andalucía y Vizcaya retrasaba sus propósitos, carencias que no se podían compensar con el grano local. La falta del anticipo que la administración debía entregar al asentista para que este

49. Orden real, Buen Retiro, 20 de mayo 1661. Copia de la Consulta de Juan de Góngora, Madrid, 19 de mayo 1661. Nuevas obligaciones de Fernando Rodríguez Lorenzana, Madrid, 19 de mayo 1661. Memorial de los asentistas del pan de munición de Galicia. AGS, GA, leg. 1.993.

50. SAnz Ayán, C.: Los Banqueros..., pp. 378-381 y 527-529.

51. Asiento ajustado con Pedro de Aguerri para la provisión de 21.000 cahices de granos, 1657. Cuentas de los granos entregados, Barcelona, 27 de noviembre 1658. Asiento de provisión de 40.000 reales de a ocho para Cataluña, 1657. Asiento para proveer en Badajoz 2.000 pares de botas y espuelas, 1657. AGS, Contadurías Generales [en adelante CG], legs. 150-152.

52. Durante los 6 meses de campaña tendría dispuestas 650 acémilas y 350 mulas de tiro para la artillería. También asistiría al ejército con dinero, 600.000 escudos en 12 mesadas.

53. Resumen de la provisión general para el Ejército de Galicia, 1663. AGS, GA, leg. 2.026. 
empezara a cumplir con el suministro de acémilas y mulas de tiro igualmente retrasó la salida en campaña del ejército ${ }^{54}$, creando importantes inconvenientes. De hecho, ante la falta de fondos el asentista solo llegó a proveer al ejército 200 cabezas de las 1.000 comprometidas, no llegando nunca a poder mantener un importante retén de pan y cebada de reserva por si sucedía cualquier imprevisto ${ }^{55}$.

La muerte del asentista, los incumplimientos y la falta de dinero hicieron que pronto el Consejo de Guerra se debiera plantear las necesidades de dicho ejército y los gastos que podía hacer frente en él de cara al siguiente asiento, rebajándose las consignaciones y las mesadas hasta prácticamente la mitad ${ }^{56}$. Las quejas llegadas desde Galicia nos informan una vez más de los procedimientos y fraudes cometidos por el asentista, que al morir dejó adeudados más de 84.000 escudos a diferentes pequeños proveedores de granos (el 16\% del monto total del asiento de pan y cebada). Una notoria infracción que desde Galicia se quería solucionar, y más cuando a raíz de las cuentas tomadas por el Capitán General Luis de Poderico se reconocía que su casa habría obtenido un beneficio de 1.567 .000 reales gracias a sus últimos asientos, sin que hubieran tenido que adelantar un maravedí. La actitud de la Casa Aguerri, la cual había cobrado más de lo que había proveído, dejando a deber dinero a muchos proveedores, había hecho que estos pequeños empresarios se negaran a vender granos al nuevo asentista ${ }^{57}$.

El nuevo asiento ajustado para el ejército de Galicia en diciembre de 1663 mantenía características parecidas al anterior, ya que se convenía con una casa con una larga trayectoria de negocios, los Montesinos. De origen criptojudío portugués, se convirtieron en tesoreros de las salinas de Galicia y Asturias, comenzando así una importante carrera como proveedores del ejército ${ }^{58}$. El jefe de la familia, Fernando, realizó su primera provisión para el ejército a comienzos de la década de 1650, cuando ajustó un importante asiento para proveer raciones a la Armada que combatía en el Atlántico y las operaciones que esta desarrolló en la Ría de Burdeos $^{59}$. Con relativo éxito Montesinos pudo cumplir con la cantidad acordada,

54. Cartas de Baltasar Pantoja y Juan de Góngora, Pontevedra, 20 de mayo y 11 de julio 1662. Nota de las cantidades que parece al Sr. Arzobispo de Santiago que son necesarias para el sustento del ejército, 23 de mayo 1662. Carta del Arzobispo de Santiago, Pontevedra, 23 de mayo 1662. AGS, GA, leg. 2024.

55. Consulta del Consejo de Guerra, 19 de junio 1662. AGS, GA, leg. 2.000.

56. Consulta del Consejo de Guerra, 19 de septiembre 1663. AGS, GA, leg. 2.029.

57. Memorial del reino de Galicia al rey. Razones del reino de Galicia y de sus particulares, diciembre 1664. AGS, GA, leg. 2.102.

58. Sanz Ayán, C.: Los Banqueros..., pp. 336-339 y 509.

59. Asiento con Fernando Montesinos para la provisión de 300.000 raciones de bastimentos en el reino de Galicia, 4 de octubre 1650. AGS, GA, libro 222, fol. 77v. Junta de Armadas, 30 de octubre y 17 de diciembre 1651. Memoria de las partidas de dinero proveídas para la compra de trigo y su flete, 22 de marzo 1651. AGS, GA, leg. 3.312. 
aunque la calidad de los géneros entregados no siempre fue buena, siendo la harina de mala calidad y estando el vino aguado ${ }^{60}$. Sus actividades convirtieron a Galicia en una de las fuentes más importantes de aprovisionamiento ${ }^{61}$, fabricándose en la villa de Neda gran parte del bizcocho consumido por la Armada del Mar Océano ${ }^{62}$, recuperando esta parte de su antiguo esplendor ${ }^{63}$. Rápidamente sus actividades en la provisión de grano continuaron, suministrando 6.000 fanegas en Ceuta ${ }^{64}$, plaza a la que siguieron proveyendo grano durante bastante tiempo ${ }^{65}$. La trayectoria de Fernando quedó truncada ante sus graves problemas con la Inquisición, que lo condenó, aunque tras pagar una multa de 10.000 ducados fue desterrado de Castilla, partiendo hacia Ámsterdam en donde vivió públicamente de acuerdo con las leyes hebraicas ${ }^{66}$. Rápidamente fue sustituido por sus hijos Manuel y Bartolomé que recuperaron los negocios familiares, expandiéndolos en poco tiempo. En 1656 se hicieron con el importante asiento para suministrar las consignaciones económicas a todos los Presidios peninsulares y norteafricanos, actividad que mantendrían durante casi una década ${ }^{67}$. En 1659 estos conseguirían mejorar las condiciones de su asiento, que pasó a estar realizado por vía de factoría, logrando importantes y lucrativas mejoras, cobrando un sueldo y diferentes gratificaciones $\sin$ apenas riesgo ${ }^{68}$.

El nuevo asiento para el sustento del ejército de Galicia implicaba el suministro de 4.800.000 raciones de pan al año, a razón de 17 maravedíes de vellón, y 80.000 fanegas de cebada y centeno por mitad para la caballería, a 17 reales la fanega, aportando también dinero y 300 acémilas y 80 mulas de tiro para el

60. Carta de Tomás de Aguirre, La Coruña, 22 de enero 1651. Carta de Fernando de la Rivaherrera, Pasajes, 1 de febrero 1651. AGS, GA, leg. 3.318. Relación por cuenta de las 300.000 raciones de la obligación del asiento de Fernando de Montesinos y lo consumido de 1 de enero a fin de marzo de 1651. AGS, GA, leg. 3.321. Carta de Fernando de la Rivaherrera, La Coruña, 14 de julio 1652. AGS, GA, leg. 3.331.

61. Cartas de Fernando de la Rivaherrera, La Coruña, 21 de abril y 14 de julio 1652. AGS, GA, legs. 3.335 y 3.331 .

62. Carta de Tomás de Aguirre, La Coruña, 29 de diciembre 1652. AGS, GA, leg. 3.335.

63. SaAvedra Vázquez, M. C.: «La formación de armadas y sus efectos a nivel territorial: el ejemplo de Galicia 1580-1640», Cuadernos de Historia Moderna. Anejos V, (2006), pp. 55-76.

64. Carta del Conde de Santiesteban, Pontevedra, 16 de febrero 1652. AGS, GA, leg. 3.334.

65. Junta de Presidios, 17 de agosto 1663. Carta del Veedor de Ceuta, 17 de mayo 1663. AGS, GA, legs. 2.029 y 2.051.

66. Sanz Ayán, C.: Los Banqueros..., pp. 336-337.

67. Título de proveedores generales de los presidios y fronteras de España a Manuel Montesinos y Bartolomé Montesinos, 10 de noviembre de 1656, repetido en 6 de septiembre 1660. AGS, GA, libro 253, fols. 258v, 266 y 235. Cuentas de lo cobrado a cargo de los Presidios por Manuel y Bartolomé Montesinos, 1657-1658. AGS, GA, leg. 1.904.

68. Prorrogación del asiento de Manuel y Bartolomé Montesinos, Madrid, 30 de mayo 1659. AGS, GA, leg. 1.993. 
carruaje y el transporte de la artillería ${ }^{69}$. Las condiciones también estipulaban los intereses de la conducción y adehalas del dinero (4\%), y los intereses de demora de las consignaciones reales ( $8 \%$ ), debiéndose consignar $1 / 3$ parte del dinero por adelantado al contado, y el resto en rentas desembarazadas cobraderas en Galicia, Asturias y León. Los asentistas también se aseguraron la prohibición de la salida de granos del reino, y el permiso para poder importar granos sin pagar derecho alguno, hasta 70.000 fanegas que podrían sacar de Cataluña, Andalucía o Italia. Sus carreteros estarían exentos de servir en la guerra, y hasta 16 de sus colaboradores gozarían del fuero militar, imponiéndose amplias condiciones para proteger sus negocios de cualquier ataque enemigo, pactando que si fuera necesario podrían embargar géneros y carruajes a sus justos precios, teniendo primacía a la hora de poder comprar los granos que capturaran los corsarios asentados en las costas gallegas. Pero sin duda la condición más importante era que los Montesinos se harían cargo de las rentas que antes habían sido de Juan Urrea, lo que les permitiría una importante libertad económica, haciéndose cargo del cobro de las Alcabalas y Diezmos del Mar por un plazo de 6 años, pagando 2.500 .000 maravedíes más que su anterior arrendador ${ }^{70}$.

Los nuevos asentistas del ejército de Galicia cumplieron por un tiempo con bastante puntualidad sus asientos y mesadas ${ }^{71}$, pero a partir de 1665 las quejas hacia su suministro aumentaron en el seno del ejército, influyendo en la desastrosa campaña bélica ${ }^{72}$. Si bien en previsión de las operaciones bélicas se había optado por aumentar las raciones de pan de 13.000 a 18.000 al día, en la primavera se comenzaron a observar problemas. Las mesadas económicas no estaban llegando, y no había reserva alguna de provisiones, no disponiendo los asentistas ni de granos ni de crédito para continuar ${ }^{73}$. A lo largo del verano la provisión de todo tipo de géneros se paralizó, al no disponer los asentistas de dinero, por lo que las autoridades militares tuvieron que tomar cartas en el asunto y requisar granos para poder suministrar lo básico a la tropa, debiéndose despedir a parte de los milicianos

69. Con un coste de 8 reales de vellón diario por cada cabalgadura, y otros 8 reales por los mozos que estaban a cargo de ellas, a razón de 3 por cada uno. Igualmente los Montesinos se encargarían de proveer 25.000 escudos al mes para atender a las pagas.

70. Condiciones del asiento con Manuel y Bartolomé Montesinos, 10 de diciembre 1663. AGS, CG, leg. 157-1.

71. Consulta del Consejo de Guerra, 23 de mayo 1664. Carta de Luis Poderico, Tuy, 9 de noviembre 1664. AGS, GA, legs. 2.054 y 2.055. Cuentas de Antonio del Rio, pagador de los ejércitos y presidios del reino de Galicia 1664-1669. AGS, CMC3, leg. 860. Cargo de lo entregado a Fernando de Luazes, tenedor de Bastimentos del ejército de Galicia, 1664. AGS, CG, leg. 438.

72. Eiras Roel, A.: «Aportación documental al Mariscal Schomberg y a la invasión portuguesa de 1665 en Galicia», en Romaní Martínez, M. y Novoa Gómez, M. A. (coords.): Homenaje a José García Oro. Santiago de Compostela, 2002, pp. 119-151.

73. Junta de Provisiones, 12 de abril y 29 de mayo 1665. AGS, GA, leg. 2.083. 
ya que no se les podía dar pan. De hecho el Capitán General afirmaba que «los Montesinos ni cumplen, ni tienen forma de hacerlo", pidiéndose explicaciones de lo que estaba ocurriendo al jefe de la casa en $\mathrm{Madrid}^{74}$. Las indagaciones realizadas por el Consejo indicaron que los asentistas no cumplían con la provisión del pan, y que incluso se habían tenido que cerrar las fábricas por no disponer de grano. En cuanto al dinero que se debía proveer, de los 310.000 escudos teóricos solo se habían puesto en las arcas 67.483, entregándose libranzas para otros 33.300, aunque de todos los efectos que se habían dado a los asentistas no disponían de más de 31.800 escudos $^{75}$. Todo ello suponía que la provisión estaba siendo un desastre, ya que los Montesinos no tenían medios para adelantar el dinero, y la Corona no disponía de rentas aprovechables, por lo que años después seguía debiendo dinero a la casa Montesinos ${ }^{76}$.

\section{El CASO EXTREMEÑo}

Al contrario de lo ocurrido en Galicia, el abastecimiento de pan del ejército de Extremadura estuvo en manos de una sola casa comercial, los Silíceo, que se afianzaron en dicha provisión combatiendo con éxito cualquier puja hostil. Procedentes de la oligarquía extremeña, supieron rápido hacerse con un hueco como proveedores del pan, estableciendo su primera negociación a finales de la década de 1640, la cual prorrogaron sin interrupción durante casi 30 años $^{77}$. Negocio que les reportó innumerables ganancias, hasta el punto de que a partir de la década 1670 establecieron contratos de mayor peso y con un ámbito internacional, proveyendo dinero en metálico en la Corte y Flandes ${ }^{78}$, y junto con otros socios se introdujeron en el comercio de esclavos negros con las Indias ${ }^{79}$. Su actividad iría creciendo a lo largo de la década de 1650, al mismo ritmo de la importancia que cobraba el ejército de Extremadura. Ya en el asiento firmado en 1657 se comprometía a proveer diariamente 10.000 raciones de pan, cantidad que cinco años después se había elevado hasta casi las 30.000 .

Para Silíceo la perpetuación como asentista era un elemento muy interesante, ya que con cada renovación se aseguraba el cobro de las consignaciones atrasadas

74. Cartas de Luis Poderico, 20, 23 y 30 de agosto, 6 de septiembre y 13 de octubre 1665. Carta de Juan de Otáñez, Madrid, 23 de septiembre 1665. AGS, GA, leg. 2.103.

75. Junta de Provisiones, 22 de octubre 1665. AGS, GA, leg. 2.083.

76. Consulta del Consejo de Guerra, 7 de noviembre 1667. AGS, GA, leg. 2.131.

77. SAnz Ayán, C.: Los Banqueros..., pp. 390-392 y 534; y «La problemática del abastecimiento de los Ejércitos de Extremadura y Cataluña durante 1652» en Temas de historia militar: ${ }^{\circ}$ Congreso de Historia Militar. Zaragoza, 1988, vol. 2, pp. 221-236.

78. AGS, CMC3, leg. 60.

79. Abreu y Bertodano, J. A.: Colección de los Tratados de Paz, alianza, garantía... Reinado de Carlos II. Parte II, Madrid, 1751, pp. 127 y ss. 
de anteriores acuerdos, intentaba ponerse al día con las raciones que no había entregado por falta de demanda o incluso negociaba la remisión a favor de la Corona de fondos no cobrados como elemento de rebaja en nuevas posturas. Sus contratos se caracterizaron por el detalle, ante lo bien que conocía las dificultades de su contrato y las rentas sobre las que se cimentaba el cobro, por lo que siempre intentó encontrar las rentas extremeñas más desembarazadas, extendiéndose luego a otras regiones limítrofes al mismo ritmo que sus consignaciones crecían. En 1657 se comprometió a entregar 3.660 .000 raciones al año a razón de 14 maravedíes, bajo la condición de que la cifra se incrementaría hasta los 17 en caso de ser suministradas a ejércitos de campaña o cuando las tropas entrasen en país enemigo. La adehala se fijó en el $4 \%$, y los intereses de conducción y los anticipos por consignaciones inciertas en un $8 \%$. Todo ello hacía que los intereses y adehalas supusieran el $17 \%$ del coste total, posible beneficio al que había que sumarle las cantidades que se podrían obtener al elaborar pan a un menor precio ${ }^{80}$.

Tabla III. Costes y beneficios previstos del asiento firmado con Sebastián Silíceo en 1657

\begin{tabular}{|l|c|}
\hline \multicolumn{1}{|c|}{ Costes e intereses } & Coste en maravedíes de Vellón \\
\hline Coste de 3.666.000 raciones de pan & 51.240 .000 \\
\hline Incremento del coste durante la campaña & 7.000 .000 \\
\hline Intereses de conducción (8\%) & 4.659 .200 \\
\hline Adehala (4\%) & 2.329 .600 \\
\hline Intereses por anticipación (8\%) & 4.659 .200 \\
\hline Cantidades atrasadas de otros asientos & 5.597 .366 \\
\hline TOTAL: & 75.485 .366 \\
\hline
\end{tabular}

Fuente: AGS, GA, leg. 1.913 y AGS, CG, leg. 150-1.

Al cumplir más o menos con regularidad sus asientos, Silíceo se fue haciendo una figura esencial para el buen gobierno del ejército ${ }^{81}$, ya que el pan era una pieza fundamental de maquinaria bélica. Durante los primeros meses de 1663 llegó al Consejo de Guerra la noticia de los problemas que estaba manteniendo el asentista para cobrar los fondos que se debían proveer, al haber salido muchos inciertos. La noticia hizo cundir el pánico, ya que se reconocía que sin el pan

80. Junta de Guerra de España, 11 y 21 de enero 1657. Capitulaciones del asiento con Sebastián García Silíceo, 7 y 21 de enero 1657. AGS, GA, leg. 1.913. Diversos contratos y capitulaciones, 1657. AGS, CG, leg. 150-1.

81. Carta del Duque de San Germán, Badajoz, 16 de febrero 1657. AGS, GA, leg. 1.894. 
y la cebada el ejército no podría salir en campaña, y de nada servirían todas las prevenciones realizadas, los fondos gastados y los miles de hombres que estaban llegando de todas partes para formar un nuevo ejército ${ }^{82}$. El consejo determinaba que este asiento era "principal», por lo que en su resolución se instaba a que se diera solución al problema de manera urgente, para que el ejército se pudiera poner en campaña sin dilación. Si bien se le había adelantado al menos una cuarta parte del total, el asentista no estaba recibiendo buena parte de lo consignado en rentas debido a que ese dinero se estaba usando para otras cosas. Uno de los problemas -recurrente en regiones sometidas a la presión de la guerra-, era que muchas rentas situadas en Extremadura y Andalucía se habían empleado para pagar los alojamientos de las tropas y su tránsito hacia el frente. Otra complicación, que progresivamente se iría repitiendo en las sucesivas campañas, fue que el aumento de la demanda -9.000 .000 raciones al año-, había hecho que se debiera comprar trigo fuera de Extremadura, encareciéndose mucho el precio debido al transporte terrestre, ya que trajinar una legua una fanega de trigo costaba 14 maravedíes ${ }^{83}$.

Pero sin duda buena parte de las quejas del asentista eran infundadas, y se aprovechaba de su situación de monopolio y de la necesidad de la monarquía, ya que si bien muchas partidas no se estaban cobrando, entraba dentro del contrato el cobro de intereses por los retrasos. De hecho, la comprobación de cuentas de su asiento de 1658 incluso era a favor de la real hacienda, alcance que quedaría olvidado por la contaduría hasta 1667. Pero lo habitual era lo contrario, que la Corona siempre adeudara algunas cantidades ${ }^{84}$. Tampoco tenía excesiva justificación el incremento del precio ante la carestía, ya que ese año se estaba dando 27 maravedíes por cada ración, cuando seis años antes las daba a 14, y en Galicia en ese año se estaban pagando a 17. Era lógico que el rudimentario transporte, a base más de acémilas que de carretas, encareciera el valor de cualquier cereal, problema que no se tenía cuando la provisión se podía establecer por mar en ejércitos como los de Galicia o Cataluña. También el aumento de la demanda extremeña había elevado los precios del grano, y si bien durante los primeros años de la contienda

82. Solo entre 1660 y 1663 habían llegado a la península 11.000 italianos para servir en Extremadura, contingente al que habría que añadir los españoles, alemanes, valones, irlandeses y sujetos de otras naciones que fueron reclutados durante esos años: Rodríguez HERNÁNDEZ, A. J.: «Al servicio del rey. Reclutamiento y transporte de soldados italianos a España para luchar en la Guerra contra Portugal (1640-1668)», Guerra e pace in età moderna. Annali di storia militare europea 4 (2012) pp. 229-275.

83. Memorial de Sebastián Silíceo, s. f. Consulta del Consejo de Guerra, 6 de marzo 1663. Junta de Provisiones, 15 de marzo 1665. Demostración y cuenta de los portes de las conducciones de granos, Zafra, 5 de marzo 1663. AGS, GA, leg. 2.026.

84. Cuentas y alcances de varios asientos de Sebastián Silíceo, 1658-67. AGS, CMC3, leg. 59. 
la demanda de grano del ejército fue asumida regionalmente ${ }^{85}$, ahora era necesario traer trigo de Castilla o Andalucía.

La solución a dicho problema estaba en acelerar la compra de grano, adquiriéndolo inmediatamente después de la cosecha ${ }^{86}$, ya que en ocasiones la prerrogativa del asiento de prohibir la saca de granos no funcionaba debido a que muchos vendedores no estaban de acuerdo con el precio ofrecido. Ante las posibles incertidumbres, y el mal resultado bélico de la campaña de 1663 -en parte ante el deficiente aprovisionamiento- la Corona incluso optó por comprar directamente granos en la provincia. Para ello realizó repartos entre los diferentes distritos, para intentar así proveer las guarniciones que se encontraban en territorio portugués y el asentista ponía reparos en abastecer. De esta manera se consiguió comprar trigo y cebada a muy buen precio, reduciendo el coste de la fanega de trigo ${ }^{87}$ de 30 a 24 reales, y la de cebada de 20 a $14^{88}$, acciones que también podían ser emprendidas por los asentistas. En otros casos se procedió a traer grano de zonas más alejadas como Sicilia y Nápoles ${ }^{89}$. Este se descargaba en Cádiz y era transportado a Extremadura desde Sevilla, lo que encarecía el precio a pesar del bajo coste en origen ${ }^{90}$.

A pesar de las constantes incertidumbres, lo cierto es que el asentista fue cumpliendo lo acordado, y con cierta habilidad se fue adaptando a las necesidades del ejército, intentando así hacerse más imprescindible ${ }^{91}$. En abril de 1660 sus representantes en Madrid elevaban un memorial al consejo en el que afirmaban que en los primeros nueve meses de su asiento había entregado el $80 \%$ de las raciones acordadas, por lo que al ritmo presente $-y$ ante el inicio de las operaciones estivales que harían aumentar el ejército-, no habría pan para todos, ya que diariamente entregaba 11.970 raciones, cuando las contratadas eran 10.000. La noticia generó la queja de los proveedores del ejército, ya que a fin de cuentas el interesado era

85. White, L.: War and Government in a Castilian province: Extremadura, 1640-1668. Tesis doctoral inédita, East Anglia, 1985, pp. 283-288.

86. Consulta del Consejo de Guerra, 20 de abril 1663. Carta de don Juan de Austria, Zafra, 13 de abril 1663. Carta de Sebastián Silíceo, Sevilla, 9 de abril 1663. AGS, GA, leg. 2.027.

87. Se consideraba que con cada fanega de trigo se podían elaborar 50 panes de munición de libra y media de peso.

88. Junta de Provisiones, 3 y 24 de septiembre 1663. Relación de la forma de establecer las compras en Extremadura. Carta de Juan de Córdoba, Mérida, 29 de agosto 1663. AGS, GA, leg. 2.029.

89. Orden Real, Madrid, 7 de septiembre 1663. AGS, Estado [en adelante E], leg. 3.286, fol. 180. Consulta del Consejo de Estado, 27 de enero 1664. Relación de las remesas que se han hecho este año por todo diciembre de 1663. AGS, E, leg. 3.287, fols. 7 y 10. Cartas del Cardenal de Aragón, Virrey de Nápoles, Nápoles, 6 de diciembre 1664 y 19 de febrero 1665. Cebada que se ha embarcado en los infrascritos puertos y bajeles, Nápoles, 1665. AGS, Estado, leg. 3.288, fols. 31, 54 y 55.

90. Relación del trigo, cebada y harina remitido desde Sevilla, Badajoz, 23 de agosto 1664. Carta del Veedor general, Badajoz, 23 de agosto 1664. AGS, GA, leg. 2.055.

91. Junta de Provisiones, 11 de mayo 1665. Carta del Marqués de Caracena, Mérida, 2 de mayo 1665. AGS, GA, leg. 2.083. 
quien estaba informando de lo entregado y no los administradores del ejército. Independiente de la posible polémica, el asentista pronto renovó su asiento, aumentando su volumen y continuando con los precios acordados ${ }^{92}$. En muchos casos sus contratos se caracterizarían por llegar a entregar más de lo acordado previamente, lo cual no deja de ser algo novedoso en el mundo de los asientos, en donde generalmente los empresarios no llegaban a cumplir por completo con lo estipulado. Para el asiento firmado a mediados de 1660 llegó a entregar 220.708 raciones de más en pan, y otras 54.000 en trigo ${ }^{93}$.

El volumen de las raciones de pan entregadas por Silíceo no dejó de aumentar desde la década de 1660, y en los 5 meses finales de 1661 entregó al ejército más de tres millones de raciones, lo que suponía más de 20.000 al día ${ }^{94}$. Tres años después acordaba entregar a la administración diez millones de raciones al año, asiento que cumplió gracias a su capacidad para reunir grandes cantidades de trigo en Extremadura, pero también en la Mancha y Salamanca, lo que claramente hizo que los costes aumentaran ante el gasto de transporte, multiplicándose su precio a lo largo de los años ${ }^{95}$. Parte del éxito de su provisión se producía por su capacidad de negociar para conseguir que los fondos suministrados por la Corona fueran efectivos, y desde 1662 exigió que una tercera parte del coste de sus asientos se entregara al contado. En mayo de 1664, según afirmaba el propio interesado, la Corona le había facilitado la mayor parte de las cantidades pactadas y solo restaban 50.257 escudos - de los 913.796 acordados-a falta de tres meses por terminar con la provisión. Al exigir que una tercera parte fuera al contado, otra en anticipaciones a cargo de otros asentistas, y la última parte en consignaciones, había conseguido que la monarquía cumpliera con rapidez, no estando a expensas de poder cobrar el dinero que producían las rentas reales, que a menudo se empleaba localmente para pagar el alojamiento de las tropas y su reclutamiento ${ }^{96}$.

92. Carta de Juan de Góngora, Madrid, 3 de mayo 1660. Relación jurada y firmada de Sebastián Silíceo del pan que proveído desde 1 de agosto 1659 hasta fin de marzo 1660, Madrid, 30 de abril 1660. AGS, GA, leg. 1.970.

93. Cuentas de lo que se ha obligado a proveer en 1660. AGS, CMC3, leg. 59. Carta de Sebastián de Silíceo, Badajoz, 18 de mayo 1660. AGS, GA, leg. 1.979.

94. Certificación a Sebastián Silíceo 1661. AGS, CMC3, leg. 60.

95. Memorial de Sebastián Silíceo, Madrid, mayo 1664. Relación jurada del trigo, harina y bizcocho, y otra del pan entregado, Badajoz, 26 de mayo 1664. AGS, GA, leg. 2.054. Cuentas de Sebastián Silíceo de la provisión del pan de munición de Extremadura 1665-67. AGS, CMC3, leg. 2.663, fol. 9 .

96. Respuesta que da Sebastián Silíceo sobre la cuenta de su asiento, Badajoz, 25 de mayo 1664. AGS, GA, leg. 2.054. Cuentas y capitulaciones de los asientos de 1662, 1663 y 1666. AGS, CMC3, leg. 60. 
Tabla IV. Asientos de pan ajustados por la Casa Silíceo para proveer el ejército de Extremadura

\begin{tabular}{|c|c|c|}
\hline Año & Raciones de pan (en un año) & Precio por ración (en maravedíes de vellón) \\
\hline 1657 & 3.660 .000 & 14 (+2 en campaña) \\
\hline 1658 & 4.650 .000 & 17 \\
\hline 1659 & 3.650 .000 & 28 \\
\hline 1660 & 4.380 .000 & 28 \\
\hline 1662 & 5.460 .000 (por 9 meses) & 30 \\
\hline 1663 & 9.000 .000 & 27 \\
\hline $1663-64$ & 10.000 .000 & 23 \\
\hline 1666 & 7.300 .000 & 51 \\
\hline
\end{tabular}

Fuente: AGS, GA, leg. 2.054. AGS, CMC3, legs. 59, 60 y 2.663. AGS, CG, legs. 150-1 y 157-2.

En ocasiones esta clase de suministros generó el interés de otras casas de negocios, lo que beneficiaba a la Corona, ya que podía renegociar un mejor precio. En agosto 1663 los Silíceo se debieron enfrentar a la casa de los Aguilar, encargados por aquel entonces del abastecimiento de cebada para la caballería del ejército de Extremadura ${ }^{97}$, que pujaron por hacerse con el asiento de pan. En un primer momento los Silíceo pretendían que los diez millones de raciones se pagaran a razón de 30 maravedíes, pero pronto la competencia bajo tres maravedíes por ración, estableciéndose repetidas ofertas de rebaja que hicieron que al final los Silíceo debieran conformarse con 23 maravedíes y la renuncia al cobro del $4 \%$ de adehala para poder mantener su negocio de aprovisionamiento, ya que la Junta de Provisiones -aunque consideraba que Silíceo había cumplido bien y era un hombre muy práctico y avezado en dicho ministerio-, parecía decida en que el ahorro era lo más importante ${ }^{98}$.

Al beneficio económico propio de cualquier asiento se le sumaban las posibilidades honoríficas más intangibles pero que podían suponer una ganancia que incluso se medía en maravedíes. Así, a partir de 1657 -cuando se fue afianzando en la provisión-, reclamó la concesión de dos privilegios de hidalguía que el propio asentista valoraba en 1.125.000 maravedíes cada uno, cantidad que la Corona

97. Orden Real, Buen Retiro, 29 de enero 1662. Condiciones del Asiento, 18 de enero 1662. AGS, GA, leg. 2.020.

98. Junta de Provisiones, 26 de agosto 1663. Carta de Miguel de Salamanca, Madrid, 2 de agosto 1663. Oferta de Alonso y García de Aguilar, 21 de agosto 1663. Carta de Sebastián Silíceo, 23 de agosto 1663. AGS, GA, leg. 2.029. Condiciones del asiento, 30 de septiembre de 1663. AGS, CG, leg. 157-2. 
debería abonar si no se concedía lo pedido. Al final solo se le dispensó uno ${ }^{99}$, pese a que en esos momentos las hidalguías no estaban en venta ante las quejas de las Cortes de Castilla ${ }^{100}$. Dichas concesiones fueron una tónica habitual, y fueron creciendo al afianzarse en la provisión, al mismo tiempo que la monarquía tenía más problemas para pagar, ya que dichas mercedes tenían un valor de mercado. La primera experiencia de 1657 no fue como el asentista esperaba, ya que aún en 1662 el agraciado con la hidalguía -Pedro Esteban Nieto Guerrero, vecino de Almendralejo-, todavía no la gozaba ante los reparos del consejo, por lo que este sujeto le reclamaba la prometida hidalguía o el pago del grano que le había vendido. Pese a ello, Silíceo volvió a utilizar esa práctica en el asiento que ajustó en 1666, reclamando otra hidalguía al precio habitual de 3.000 ducados. En cambio, en el ajustado en 1662 introdujo otro elemento, la venta de regidurías, ya que en ese año pedía la concesión de tres en las villas de Jerez de los Caballeros, Valencia de Alcántara y Ágreda, ajustadas al precio de la última compra, sacándose los costes a cargo de las consignaciones no cobradas o inciertas. En 1666 pidió una regiduría de Badajoz de las acrecentadas en las últimas cortes a precio de mercado ${ }^{101}$, y en el asiento que llevó a cabo en 1667 exigía otras 5 en diferentes ciudades y villas. Esa política de concesiones no solo le servía para intentar cobrar ante las penurias de la hacienda, sino que así podía compensar a sus colaboradores y recobrar apoyos por parte de las autoridades locales a la hora de comprar granos ${ }^{102}$.

A estos beneficios venales habría que sumarle otros igualmente intangibles pero muy interesantes en una región que padecía innumerables cargas debido a la guerra, como la exención de alojamientos y repartimientos de cargas locales -para sí mismo, su familia y buena parte de sus colaboradores-, o la posibilidad de ampararse en el fuero militar y otros beneficios jurídicos como que sus causas tuvieran un juez privativo ${ }^{103}$. Beneficios que se sumaban al hecho de que varias personas de cada lugar donde se proveía pan, a su elección, quedarían exceptuados de ser apremiados y molestados para salir como milicianos, hacer guardias o alojar tropas ${ }^{104}$. Distinción a la que se sumaba la honorífica de poder portar armas prohibidas en la Corte para su hermano y otros colaboradores que representaban sus negocios en Madrid ${ }^{105}$.

99. Ibidem. AGS, CG, leg. 150-1.

100. Domínguez Ortiz, A.: La Sociedad Española en el siglo XVII. Vol. I, Madrid, 1963, pp. 182-183. Thompson, I. A. A.: «The purchase of nobility in Castile, 1552-1700», Journal of European Economic History 8 (1979), pp. 313-360.

101. Capitulaciones de los asientos de 1662 y 1666. AGS, CMC3, leg. 60.

102. SAnz Ayán, C.: Los Banqueros..., p. 391.

103. Orden Real, Buen Retiro, 21 de enero 1662. AGS, GA, leg. 2.020.

104. Cuentas y alcances de varios asientos de Sebastián Silíceo, 1658-1667. AGS, CMC3, leg. 59.

105. Capitulaciones y cuentas del asiento ajustado en 1666. AGS, CMC3, leg. 60. 


\section{FraUde, CONTINUIDAD Y CRÍTICAS}

Si bien gracias a la privatización de la provisión pan el ejército podía librarse de la penuria, la mala gestión continuaba siendo la tónica ante las debilidades de la administración estatal y su escasa entidad y volumen. La contaduría era capaz de controlar que el asentista remitiera el pan necesario, y las raciones entregadas se contabilizaban, pero otra cosa diferente es que el fraude no estuviera a la orden del día. Los proveedores no eran capaces de controlar todo el proceso, ya que no había suficientes, por lo que en muchos casos los asentistas y sus agentes no tenían a quien entregar las raciones y debían nombrarse ad hoc personas para ejecutar esa función de control. Otro problema era que, a falta de muestras diarias, o más pormenorizadas, se entregaba el pan a cada compañía según la última estimación de efectivos, la cual nunca solía ser real. Esto daba pie a que se entregaran más raciones de las necesarias, al no restarse nunca las bajas o deserciones. En 1663 se estimó que a lo largo del año se habían entregado 63.119 raciones de pan de más, fraude que no dejaba de ser excesivo aunque difícil de parar ${ }^{106}$.

El problema no tenía que ver con la privatización del suministro, sino con los oficiales del ejército, que en muchos casos eran los principales causantes del fraude, incluyéndose en este a los veedores ${ }^{107}$. Hasta la orden cursada en 1656, las raciones se entregaban a los capitanes y oficiales que las distribuían entre sus soldados. Pero en ocasiones estos se quedaban con una parte, o permitían a sus hombres desertar o irse con licencia para apropiarse de sus raciones, creando innumerables abusos. A partir de esa fecha se estableció que para evitar fraudes las raciones de pan y cebada se debían entregar en mano a cada soldado a través de la proveeduría ${ }^{108}$. Esto no hizo que los fraudes cesaran y que se siguieran consumiendo más raciones de las que las muestras del ejército indicaban ${ }^{109}$, a pesar de que en algunos casos se actuó contra los implicados, los cuales fueron reformados perdiendo el mando efectivo de sus compañías ${ }^{110}$.

Para atajar este problema lo lógico era aplicar sistemas parecidos al que empleaban los holandeses y príncipes alemanes, que en vez de pan dos días a la semana daban dinero al soldado para que estuviera más asistido, evitándose así fraudes y fugas. Si bien se intentó imponer este sistema en el ejército de Flandes, al final no

106. Certificaciones de Pedro Peredo y Juan Bautista Zavala, veedor y contador de los presidios de Extremadura, Badajoz, 4 de junio 1663. AGS, CMC3, leg. 59.

107. Sobre la acusación de que un veedor general se había beneficiado del contrato del pan, cometiendo fraude: MAFFI, D.: «L'Amministrazione della Finanza Militare nella Lombardia Spagnola: I Veedores e I Contadores dell'Esercito (1536-1700)», Storia Economica 5 (2002), pp. 54-106.

108. Orden Real al Duque de San Germán, 16 de mayo 1656. AGS, GA, libro 250, fol. 155.

109. Indagaciones sobre el pan de munición entregado, 3 de marzo y 2 de mayo 1660. AGS, GA, libro 268 , fol. $50 \mathrm{v}$ y 67.

110. Orden al Condestable de Castilla, 22 de junio 1666. AGS, GA, libro 296, fol. 27v. 
se instauró ya que se creía que los fraudes serían mayores y que el dinero sería empleado en otras cosas como el juego, haciendo que finalmente los soldados estuvieran peor asistidos ${ }^{111}$. En Flandes el pan continuó siendo suministrado por contratistas privados que incluso atendieron a la demanda de los ejércitos aliados $^{112}$, manteniéndose este sistema en Cataluña y Milán ${ }^{113}$.

La crítica de los tratadistas militares al sistema fue mordaz, y hablaba de que «el modo que se ha introducido para juntar los víveres por medio de hombres de negocios y assientos, es oy uno de los que más coopera a la falta de ellos». Según algunos el problema estaba en los propios negociantes, ya que

quando estos asentistas eran menos maliciosos y de más conciencia, y havia dinero prompto, eran útiles. Oy son absolutamente sañosos, encarecen los frutos, compran lo peor, hacen pan pestilencial que infecciona los exércitos, llevan precios excesivos, probehen mal, y como es sabido la postura no alcanzan los medios a la paga, y faltando ésta justifican la omisión ${ }^{114}$.

Para muchos tratadistas militares que criticaron los asientos la solución no era que la provisión se realizara a través de la real hacienda, sino que se volviera a entregar a los soldados sus sueldos al completo, alegando que en los primeros tiempos del ejército de Flandes se hacía así. Tras su percepción de que todo tiempo pasado fue mejor no tenían en cuenta el importante aumento del tamaño de los ejércitos y sus costes, y que pese a todo el suministro de pan había sido una acción coherente que al menos daba a los soldados lo esencial para subsistir. Solo en periodos muy concretos y excepcionales la administración se hizo cargo directamente de la gestión y el suministro del pan, como en 1681, cuando los problemas derivados de la bajada de la moneda pusieron en quiebra todo el sistema de asientos basado en consignaciones de rentas. En el verano de ese año las guarniciones extremeñas debieron ser proveídas directamente por la Corona, que en cada lugar se encargó de encontrar personas que elaboraran el pan necesario. Este se pagó a unos precios sensiblemente inferiores a los 24 maravedíes que hasta el momento se estaban dando al asentista, ya que cada ración, según el lugar de compra, podía valer entre 15 y 22

111. Consulta del Consejo de Estado, 25 de febrero 1681. AGS, Estado, leg. 3.866.

112. A finales de la década de 1670 el ejército inglés que combatía en Flandes era proveído por asentistas que previamente habían trabajado para la Corona: CHILDs, J.: The British Army of William III, 1689-1702. Manchester, 1987, p. 250.

113. Espino López, A.: Catalunya durante el Reinado de Carlos II. Política y guerra en la frontera catalana, 1679-1697. Barcelona, 1999, pp. 43 y 318-321. STORRs, C.: «The Army of Lombardy and the Resilience of Spanish Power in Italy in the Reign of Carlos II (1665-1700) Part Two», War in History 5 (1998), pp. 1-22.

114. Restablecimiento de la disciplina militar al pie antiguo y reformación del ejército conforme a la ordenanza vieja y victoriosa de España, (hacía 1660). Biblioteca Nacional [en adelante BN], mss. 9.394, fol. 341 . 
maravedíes en junio, y de 10 a 15 en julio. El ahorro relativo a esos meses ascendió a 40.589 reales en junio, y 63.246 en julio, datos que reflejan la enorme fluctuación de precio ante la reciente cosecha. El ahorro era importante gracias al reajuste de precio debido a la estación, pero también al menor gasto en adehalas e intereses y a que seguramente no se estaba contabilizando el coste de los sueldos de los ministros empleados en la ejecución. Pero el problema estaba en que en invierno los precios podían dispararse, no se aseguraba el suministro y que fundamentalmente se estaba atendiendo a este gasto gracias a los pocos fondos enviados y al crédito personal de los mandos de la frontera ${ }^{115}$. Los asientos, a pesar del mayor coste unitario de la ración de pan, permitían asegurar el precio y el abastecimiento, protegiéndose el suministro de la falta de liquidez directa del ejército.

\section{Disparar con Pólvora Del REY}

La pólvora fue un producto básico para cualquier estado, por lo que desde el reinado de los Reyes Católicos su fabricación en España fue controlada, sometida a estanco y convertida en una regalía de la Corona. Desde la primera mitad del siglo XVI su manufactura fue ejecutada por la administración, siendo un monopolio real, produciéndose en fábricas reales creadas a iniciativa de la monarquía. Incluso a lo largo del siglo Xvi la Corona estableció nuevas fábricas, prohibió la exportación de pólvora ${ }^{116} \mathrm{e}$ incluso compró la mina de azufre de Hellín para asegurarse la provisión ${ }^{117}$. Si bien en un primer momento estas fábricas instaladas fundamentalmente en Málaga, Burgos y Cartagena podían hacerse cargo de la demanda peninsular, desde finales del siglo xvi se duplicó el consumo de pólvora, por lo que se debió recurrir a los asientos para poder atender a las crecientes necesidades bélicas, contratos que a la altura de 1587 ya suministraban el $25 \%$ de la pólvora ${ }^{118}$. En un primer momento los asientos tuvieron una escala muy limitada, con un ámbito local o regional ${ }^{119}$. Las concesiones se convirtieron en monopolios para los asentistas, que a cambio de unas limitadas aportaciones de pólvora tenían la exclusividad de su venta al por menor en sus zonas de actuación, además de enormes privilegios

115. Consultas del Consejo de Guerra, 11 de julio, 6, 13 y 29 de agosto 1681. Relación de la forma en que se ha dispuesto y de lo que ha importado la provisión del pan y cebada, junio 1681. AGS, GA, leg. 2.510.

116. Thompson, I. A. A.: Guerra y decadencia..., pp. 288-293. Sánchez Gómez, J.: «Abastecimiento y desabastecimiento de pólvora en España en el siglo XVI», Studia Historica. Historia Moderna 3 (1985), pp. 55-62.

117. AGS, libro 57, fol. 114v.

118. Thompson, I. A. A.: Guerra y decadencia..., pp. 47 y 305-306.

119. Sobre los asientos ajustados en Granada en 1584 y 1589: JimÉnez Estrella, A.: «Asentistas militares y fraude en torno al abastecimiento de pólvora en el reino de Granada (siglo XVI)», Investigaciones históricas: Época moderna y contemporánea 30 (2010), pp. 11-29. 
a la hora de comprar salitre a los productores ${ }^{120}$. Este sistema terminó eliminándose a mediados de la década de 1620, ante las quejas de las Cortes de Castilla. En 1632 las principales fábricas de Málaga, Cartagena y Pamplona continuaban en manos de la Corona, pero desde el Consejo de Guerra se estableció que estas se ofrecieran en asiento (salvo Cartagena, en donde los costes productivos eran más bajos), ya que la experiencia demostraba que el coste de las municiones elaboradas a cargo de las fabricas reales era más elevado que los precios de mercado ${ }^{121}$. Parte del problema estaba en los propios oficiales reales y sus gajes, ya que el sueldo del administrador de los salitres del reino de Granada y los obispados de Córdoba y Jaén fue prácticamente el $15 \%$ del total del dinero gastado, a cambio de la modesta cifra de 1.100 quintales comprados anualmente a los salitreros privados ${ }^{122}$.

Desde 1635 la mayor parte de las fábricas reales de pólvora empezaron a estar gestionadas por asentistas privados, como la de Málaga, que recibían el salitre a cargo de la administración. Este se encargaba de producir la pólvora aportando el resto de los elementos (azufre y carbón), recibiendo 65 reales y 6 maravedíes por cada quintal elaborado. Pero la producción era escasa al depender demasiado del salitre recibido, alegando el asentista demasiadas mermas ante incendios y humedades. Sin terminar de cumplirse el asiento, a finales de diciembre de $1639^{123}$, se estableció un asiento general de todos los salitres y fábricas de pólvora de Castilla en la cabeza del genovés Antonio Graffion ${ }^{124}$. Esto significaba -al menos en la pólvora producida en Castilla-, que los asientos se convirtieron en generales, agrupando a todas las fábricas y molinos que producían pólvora, independientemente de su ubicación. Todas las fábricas quedaban en manos de un solo asentista, que debía dar cuenta de todo el material que encontraba al llegar ${ }^{125}$. A través de este

120. La base fundamental de la pólvora era el salitre, y a los asentistas se les daba por válido que por cada quintal se emplearan 80 libras de salitre, 11 de azufre y 14 de carbón, siendo la merma total de 5 libras.

121. Thompson, I. A. A.: Guerra y decadencia..., pp. 305-313. En Flandes, por estas mismas fechas, se intentó recuperar la provisión de manos privadas: Esteban Estríngana, A.: «El suministro de pólvora en el ejército de Flandes. Sobre la gestión directa y delegada del aprovisionamiento militar (siglo XVII)» en García Hernán, E. y Mafri, D. (eds.), Guerra y Sociedad en la Monarquía Hispánica. Política, Estrategia y Cultura en la Europa Moderna (1500-1700). Madrid, 2006, vol. II, pp. 473-522.

122. Relación de cuentas tocantes a la administración de los salitres del reino de Granada, obispados de Córdoba y Jaén, 1626-1640. AGS, CMC3, leg. 742, fol. 2.

123. Cuentas de Francisco Lorenzo de Lara, asentista de la fábrica de pólvora de Málaga, 16351639. AGS, CMC3, leg. 742, fol.1.

124. Thompson, I. A. A.: «Aspectos de la organización naval y militar durante el ministerio de Olivares» en J. Elliott. y García SAnz, A (coords.): La España del Conde Duque de Olivares. Valladolid, 1990, pp. 249-274.

125. Título de administrador general de las fábricas de salitre y pólvora, 12 de diciembre 1639. AGS, GA, libro 176, fol. 161v. 
sistema la Corona quería acabar con los problemas de provisión, centralizándola y dejando en manos del asentista todos los derechos sobre el salitre que se producía en Castilla durante los 5 años de vigencia del contrato, esperando que se pudieran entregar 41.000 quintales de pólvora. Según las cuentas del asentista, este entregó poco más de la mitad de lo comprometido (22.866 quintales y 65 libras), a 160 reales de vellón por quintal, un precio bastante competitivo ya que el asentista había insistido en recibir 200 reales. El gran problema fue que, aunque se habían establecido consignaciones de rentas para hacer frente al pago del asiento, la Corona no estaba suministrando el dinero necesario, incrementándose los costes de transporte al tener que conducir la pólvora a cargo del asentista hasta los lugares indicados, por lo que al terminar el asiento la corona debía al asentista 5.251.288 maravedíes. La privatización tuvo un efecto positivo, la instalación a cargo del asentista de una fábrica de pólvora en Villanueva de Alcardete para procesar los buenos salitres que se producían en el Priorato de San Juan y que hasta el momento se debían conducir a Málaga o Murcia ${ }^{126}$, despuntando esta última ciudad como la gran productora durante este periodo, elaborándose allí 3/4 partes del total ${ }^{127}$.

El asiento, a pesar de la muerte de Antonio Graffion, a partir de 1649 continuó en manos de su viuda, estableciendo bases más profundas que se repetirían en los restantes asientos generales ajustados a lo largo del siglo. Por un lado se comprometía a entregar a la monarquía 50.000 quintales de pólvora en 10 años, a razón de 13 escudos el quintal, y como gracia la concesión de un hábito de una de las tres Órdenes Militares de Castilla para la persona que se casase con Catalina Graffion, su hija. La corona conseguía un moderado precio, pero a cambio concedía al asentista el control sobre la producción de salitres, prohibiendo la saca de estos de las zonas productoras, por lo que los salitreros no tenían otra opción que vendérselos al asentista, regulándose su precio a una cantidad fija (109 reales de vellón por los salitres refinados de la Mancha y 60 por los de Murcia y Granada, entregados estos sin refinar). También los asentistas se aseguraban la compra de al menos 800 quintales de azufre de las minas de Hellín a un precio bastante bajo, 30 reales el quintal. A la vez se establecía el monopolio de fabricación quedando sujeta la pólvora a un estanco, por lo que nadie en el reino la podía fabricar o vender sin permiso del asentista. Incluso los asentistas se aseguraron de arruinar a la competencia, acordando la destrucción del resto de los molinos de pólvora, persiguiendo el contrabando y estableciendo penas de embargo y destierro a los que vendieran ilegalmente. También

126. Sobre la producción de pólvora en estas dos ciudades: GIL SANJUÁN, J.: «Industrias bélicas malagueñas: la fundición de cañones y los molinos de pólvora en los siglos XVI y Xviı», Jábega 31 (1980), pp. 21-36 y Ruiz IbáñEz, J. J.: Las dos caras de Jano. Monarquí, ciudad e individuo Murcia, 1588-1648. Murcia, 1995, pp. 215-217.

127. Cuentas de Antonio Graffion, administrador general de la pólvora en Castilla, 1639-1645. AGS, CMC3, leg. 742, fol. 1. 
se reservaban la facultad de conceder derechos a terceros para poder vender o labrar pólvora. En caso de poder cumplir con las cantidades de pólvora acordada, los proveedores tenían derecho a exportar 500 quintales fuera de España, para vender a naciones amigas de la Corona sin pagar derechos. Pese a las concesiones lo cierto es que este asiento estuvo lejos de ser efectivo, y en los primeros años no llegó a producir $1 / 3$ parte de la pólvora acordada. Los asentistas se justificaban ante la falta de fondos y los problemas sucedidos en Murcia con la peste (1648) y las posteriores inundaciones (1651) que habían destruido parte de los molinos y acequias, encareciéndose los jornales a causa de la falta de población. Aunque se había instalado un nuevo molino de pólvora en Jabalí Viejo, la falta de agua había hecho que este no produjera la cantidad necesaria, ya que se había estimado que, de los 5.000 quintales anuales, 2.800 procederían de Murcia. A su vez se quejaban de que el monopolio no se estaba cumpliendo ante la introducción de pólvora desde Aragón y los puertos marítimos, además de que había molinos ilegales en el reino de Granada que los asentistas pedían expropiar para poder así cumplir con su contrato. Un acuerdo que no les estaba reportando beneficios, afirmando que cada quintal de pólvora les costaba 18 escudos y no $13^{128}$. A partir de 1652 la Corona debió tomar cartas en el asunto ante los retrasos, nombrando a varios veedores y superintendentes para los diversos partidos donde se producía la pólvora, con órdenes para que se encargaran de la buena disposición de los materiales, controlaran la fabricación y el uso de materiales correctos, además de proveer el dinero necesario ${ }^{129}$.

Desde 1653 la viuda de Graffion contó con la ayuda de otras dos personas que se hicieron cargo «de mano común» del asiento, Diego Felipe de Cuadros y Joseph Mateos Navarro, ejerciendo el primero de superintendente general de las fábricas de pólvora y el segundo de administrador general ${ }^{130}$. Esto no supuso una mejora de la provisión, que continuó siendo escasa. Tanto de Cuadros como Materos fueron encausados por la Corona, realizándose importantes indagaciones fiscales y embargándose sus bienes, aunque consiguieron que se les hiciesen buenos 19 escudos por cada quintal proveído. El único elemento positivo del asiento fue sin duda las inversiones que realizaron para mejorar las instalaciones previas, construyéndose una nueva fábrica en Alcázar de San Juan, que a la larga produciría gran cantidad de pólvora de excelente calidad ${ }^{131}$.

128. Cuentas de Ana Duque de Estrada de su asiento sobre la provisión de pólvora ajustado en 28 de octubre 1649. AGS, CMC3, leg. 3.500, fol. 1.

129. Títulos de veedor y superintendente de la pólvora de los partidos de Granada, Murcia y La Mancha, 13 de septiembre 1652. AGS, GA, libro 235, fols. 1-5.

130. Títulos despachados en Madrid, 12 de julio 1653. AGS, GA, libro 235, fols. 247-248.

131. Cuentas de José Mateos Navarro de su asiento de provisión de Pólvora, 1653. AGS, CMC3, leg. 2.186, fols. 21, 2.300 y 5. Permiso a Diego Felipe de Cuadros para fabricar un molino de pólvora en la jurisdicción de la villa de Alcázar de Consuegra, 25 de mayo 1653. AGS, GA, libro 235, fol. 205. 
A pesar de lo ocurrido en 1656 se renovó el asiento con Ana Duque de Estrada, viuda de Graffion, amparada esta vez por Marcos García de Paredes, que ejercería el título de Administrador General de las fábricas de pólvora y salitres de Castilla ${ }^{132}$. Las 41 cláusulas del asiento firmado en 1656 no hacían otra cosa que aumentar las prerrogativas de los asentistas y sus privilegios. A pesar de los incumplimientos anteriores, se comprometían a elaborar 50.000 quintales en 10 años, a razón de 17 escudos, estando obligados a poner a su costa 2.800 quintales anuales en Cartagena de las fábricas de Murcia, 800 de Granada en Málaga y 1.400 de los producidos en Alcázar de San Juan y los Prioratos en los lugares que la Corona estimase, corriendo a su cargo los portes de las primeras 20 leguas. Para asegurar el pago, el primer año se debía pagar al contado, y los restantes en consignaciones que se entregarían en las fábricas o la Corte, todo ello con la mayor prontitud posible y con el compromiso de que los asentistas no debían fabricar más pólvora de la que se pudiera labrar con el dinero suministrado. Para agilizar la cobranza de las consignaciones se establecía que uno de los ministros del Consejo de Hacienda actuaría como Juez privativo. Dentro de los acuerdos se volvía a establecer que todos los salitres producidos en las regiones sujetas al asiento -incluso si se descubrían nuevos depósitos- serían adjudicados a los asentistas, a los precios ajustados en los años antecedentes, con la prohibición de poder labrar, y vender salitre y pólvora sin licencia, estableciéndose que si los salitreros no deseaban vender su producto a los asentistas no podrían comercializar su producción y deberían arrendar sus calderas a los contratistas. De esta manera un amplísimo distrito que comprendía toda Andalucía, Murcia, Toledo, los Prioratos de San Juan, Sigüenza, Coria, Burgo de Osma, Ávila, Madrid y la Mancha quedaba en manos de los asentistas, estableciéndose penas pecuniarias y condenaciones para todos los que infligieran la norma. También se deshacían de todos los molinos que fabricaban pólvora ${ }^{133}$, especialmente en Murcia, Granada y la Mancha, reservándose solo los que estaban en la villa de Pastrana, que podrían ser arrendados por los asentistas en caso de que en verano los de Alcázar de San Juan no pudieran moler por falta de agua.

Para la protección de su estanco se prohibía la entrada de géneros procedentes de Valencia, Aragón, Navarra y otros reinos, manteniéndose un precio fijo para la pólvora fina que se vendía a particulares (entre 5 y 6 reales la libra según su procedencia y calidad), precio al que también se vendería la pólvora para el arcabuz real, con el compromiso de ofrecer a solo 3 reales la pólvora para la defensa de la costas. Los precios de venta triplicaban los que pagaba la Corona, siendo

132. Título de administrador general del asiento, 20 de enero 1656. AGS, libro 251, fol. 247. Consulta del Consejo de Guerra, 22 de diciembre 1656. AGS, GA, leg. 1.878.

133. Un ejemplo de cómo se deshacían de los molinos que les hacían competencia: Carta de Agustín Graffion, Alcázar de San Juan, 24 de septiembre 1662. AGS, GA, leg. 2.023. 
estos libres de cualquier impuesto, derecho o portazgo, exenciones que también se aplicaban a los ingredientes necesarios para la fabricación. Los estanqueros, salitreros, polvoristas, toneleros, carpinteros y administradores gozarían de las preeminencias que gozaban los artilleros y ministros de la artillería, estableciendo un juez conservador en cada uno de los tres partidos para conocer privativamente todas las causas civiles y criminales ${ }^{134}$. El nombramiento se haría por la Corona, pero los asentistas proponían tres personas por cada partido, pudiendo cambiar a estos cada año. Además se facilitaba a los asentistas la posibilidad de arrendar molinos, almacenes, proveerse de madera y azufre a unos precios justos, pudiendo importar calderas de cobre del extranjero sin pagar derecho alguno. Incluso algunas de las cláusulas servían para blindar los asientos ante los posibles imprevistos como contagios, inundaciones, incendios o falta de agua, que en caso de sucederse no quedarían obligados a suministrar el total de la provisión acordada. Como adehala del asiento, los empresarios obtendrían un hábito de las tres Órdenes Militares (a favor del hijo o la hija de García Paredes) y Ana Duque de Estrada conseguiría el indulto en sus causas ${ }^{135}$.

La mejora de las condiciones a favor del asentista no significó un mayor cumplimiento de los acuerdos, y pronto el Consejo de Guerra debió nombrar a otro administrador general ante lo mal que había cumplido García Paredes, que tampoco tenía los suficientes medios para asegurar la provisión constante de pólvora. De hecho, en los primeros 6 meses de asiento García solo había fabricado 630 quintales, mientras que el nuevo consignatario, Diego de Cervantes, había podido fabricar 1.900 quintales en los seis meses siguientes. Ante dicha situación el Consejo aprobó la modificación del asiento, por el cual solo se entregarían 4.200 quintales anuales, rebajándose el precio en un escudo ${ }^{136}$. Meses después el Consejo consideraba que se necesitaba dinero urgente para atender al desabastecimiento. En dos años y tres meses solo se habían fabricado 9.008 quintales de pólvora (1.100 en Aragón a 17 escudos de plata, 715 en Navarra a 12 escudos de plata, 663 en Orihuela al mismo precio en plata y 6.530 en Castilla a 14, 16 y 17 escudos), mucho menos de la contratada. Para ello se debía mejorar la provisión de dinero, intentado ajustarse nuevos asientos en Navarra y Orihuela para proveer al menos 1.200 quintales anuales en cada parte, a razón de 12 escudos de plata. Con estos nuevos acuerdos y el establecido en Castilla se pensaba llegar a producir 6.600

134. Muchos eran oidores de Chancillerías o Corregidores: Títulos de los tres jueces conservadores, 2 de febrero 1656. AGS, GA, libro 253, fols. 1-3.

135. Capitulaciones impresas del asiento, Madrid, 10 de febrero 1656. AGS, GA, leg. 1.894. Asiento con Marcos García de Paredes, 2 de febrero 1656. AGS, GA, libro 253, fol. 3v.

136. Pliego de Diego Cervantes sobre la continuación del asiento de pólvora, 13 de marzo 1657. Consulta del Consejo de Guerra, 16 de marzo 1657. AGS, GA, leg. 1.894. Título de administrador general, 28 de diciembre 1656. AGS, GA, libro 255, fol. 29v. 
quintales anuales que podrían atender todas las necesidades peninsulares, insulares y del norte de África ${ }^{137}$. A pesar de ello, al menos momentáneamente, se debían comprar 3.000 quintales de pólvora de Holanda, Flandes o Italia ${ }^{138}$, estableciéndose otras compras a nivel nacional a particulares de Sevilla, Málaga, Cádiz y Bilbao ${ }^{139}$.

El estanco generó importantes problemas jurisdiccionales al ser los salitres, la pólvora y otros géneros una regalía, enfrentándose las Cortes a dicho asiento y pretendiendo su derogación ante las concesiones de los nuevos servicios de millones. El problema era, según los técnicos de la artillería, que el coste de fabricar la pólvora directamente ascendería a 30 escudos el quintal frente a los 16 que se daban a los asentistas, saliendo la comprada fuera de España a 35. Ante ello recomendaban que no se hiciera novedad en el asiento, ya que el beneficio real de los asentistas estaba en el estanco de la pólvora fina, resarciéndose así de lo que perdían suministrando a la Corona ${ }^{140}$, lo que hacía que los precios fueran bajos y no se debieran dar mayores cantidades como en los ajustados previamente. Antonio de Frías también pensaba que el monopolio ajustado 25 años atrás había sido positivo, ya que el precio de venta no habían sido tan excesivo como antes, por lo que se recomendaba al rey que no se amoldara a las peticiones del Consejo de Castilla, ya que la supresión de los estancos provocaría el desabastecimiento y el aumento de precios ${ }^{141}$.

Durante la década de 1660 los asientos de pólvora de Castilla continuaron, al igual que los ajustados en Pamplona y Orihuela, mejorándose la provisión ${ }^{142}$, lo que no quitó para que fuera necesaria la importación. Ese recurso había estado presente desde siempre. Desde Flandes nunca había habido problemas para proveerla, aunque en ocasiones los precios eran desorbitados ${ }^{143}$, por lo que frecuentemente se debió adquirir en Hamburgo ${ }^{144}$, aunque siempre era más barato producirla en España. A

137. Consultas del Consejo de Guerra, 8 y 20 de agosto 1657. Relaciones de la pólvora distribuida y del dinero librado, 2 de agosto 1657. AGS, GA, leg. 1.896. Título de administrador general del asiento de pólvora de las fábricas de Orihuela, 10 de mayo 1656. AGS, GA, libro 253, fol. 85. Cuentas del asiento de pólvora de Navarra, 1656-1660. AGS, CMC3, leg. 3.489. fol. 14.

138. Junta de Guerra de España, 24 de abril 1657. AGS, GA, leg. 1.895.

139. Consulta del Consejo de Guerra, 4 de julio 1657. AGS, GA, leg. 1.896.

140. De hecho se calculaba que solo en Madrid se consumían 12.000 libras al año de pólvora fina que se proveía por los asentistas.

141. Impreso de los asentistas de la pólvora al Sr. Don Juan de Austria, 1662. Memorial de Fernando Antonio de Robles. AGS, GA, leg. 2.021. Cartas de Antonio de Frías, Veedor General de la artillería de España, Madrid, 24 de marzo y 7 de agosto 1662. AGS, GA, leg. 2.020.

142. Notas de los libros del Veedor General, marzo 1660. Consultas del Consejo de Guerra, 11 de abril 1663 y 18 de marzo 1665. Carta de Antonio de Frías, Madrid, 8 de agosto 1663. AGS, GA, legs. $1.969,2.027,2.083$ y 2.047 .

143. Carta de Miguel de Salamanca, Bruselas, 14 de julio 1641. Órdenes al Marqués de Tordelaguna, Madrid, 31 de marzo 1644. AGS, Estado, legs. 2.248 y 2.251.

144. Órdenes a Francisco de Melo, Madrid y Zaragoza, 30 de mayo y 23 de septiembre 1643.14 de julio 1641. AGS, Estado, leg. 2.250. 
partir de 1648 se pudo contar con la posibilidad de que los mercaderes holandeses la proveyeran a unos precios más moderados ${ }^{145}$, pero sin duda las llegadas más importantes venían de Italia ${ }^{146}$. La paz con Francia permitió su envío, y en 1660 arribaron a la península 3.000 quintales desde Nápoles, y otros 1.280 desde Sicilia ${ }^{147}$. De hecho para la campaña de 1662 se pidió el envío de 4.000 quintales de estas procedencias ya que entre los asientos firmados en Castilla, Navarra y Valencia no se esperaba reunir más de $5.000^{148}$. La pólvora italiana fue esencial para proveer los ejércitos y armadas que luchaban en la fase final de la guerra con Portugal, aportaciones que compensaban la baja producción de Murcia y los problemas ocasionados ante la falta de azufre y la baja calidad del producido en Hellín ${ }^{149}$. Incluso se firmaron nuevos asientos para potenciar la producción de pólvora en zonas en donde no se producían salitres, ya que todo sumaba para atender el desabastecimiento. Así, en 1663 se aprobó que los asentistas de cañones de Liérganes se hicieran cargo de producir 400 quintales anuales a razón de 18 escudos ${ }^{150}$.

Durante las décadas siguientes los asentistas de la pólvora de Castilla siguieron gozando del estanco y su monopolio, no cambiando demasiado los términos de los acuerdos ${ }^{151}$, aunque sí los asentistas, ya que en pocos casos estos renovaron o cumplieron sus acuerdos. Así, Juan Agustín Tacón se comprometió en 1671 a proveer 2.400 quintales anuales en el partido de Murcia por 10 años, pero su asiento solo duró de septiembre de ese año a julio del siguiente, entregando durante ese tiempo 501 quintales ${ }^{152}$. Años después, Antonio Sánchez de Lamadrid también debió dejar su asiento, y en los tres años que tuvo vigencia entregó 3.180 quintales, menos de lo que debía haber entregado en un año ${ }^{153}$. A comienzos de

145. Carta del secretario Galarreta para Pedro Coloma, 7 de diciembre 1647. AGS, Estado, leg. 2.256.

146. Carta del Conde de Peñaranda, Nápoles, 1 de marzo 1660. Consulta del Consejo de Estado, 22 de junio 1660. AGS, Estado, leg. 3.283, fols. 76 y 97. Consulta del Consejo de Estado, 9 de septiembre 1662. Carta del Conde de Peñaranda, Nápoles, 5 de septiembre 1662. AGS, Estado, leg. 3.285, fols. 35 y 38. Consulta del Consejo de Estado, 30 de junio 1663. Orden Real, Madrid, 24 de octubre 1663. AGS, Estado, leg. 3.286, fols. 57 y 183. Carta del Conde de Peñaranda, Nápoles, 17 de diciembre 1663. Orden Real, Madrid, 12 de noviembre 1664. Consulta del Consejo de Guerra, 22 de diciembre 1664. AGS, Estado, leg. 3.287, fols. 9, 150 y 152. Carta del Cardenal de Aragón, Nápoles, 27 de diciembre 1664. AGS, Estado, leg. 3.288, fol. 15. Consulta del Consejo de Estado, 24 de abril 1668. AGS, Estado, leg. 3.29, fol .44.

147. Carta de Antonio de Frías, Madrid, 2 de septiembre 1660. AGS, GA, leg. 1.970.

148. Nota de los géneros necesarios, 1662. AGS, GA, leg. 2.019.

149. Carta de Antonio de Frías, Madrid, 7 de septiembre 1662. AGS, GA, leg. 2.020.

150. Consulta del Consejo de Guerra, 13 de agosto 1663. AGS, GA, leg. 2.029.

151. Acuerdos del asiento tomado con el proveedor general Juan de Urrea, 30 de julio 1680. AGS, GA, libro 361, fol. 31 .

152. Cuentas de Juan Agustín Tacón, 1671. AGS, CMC3, leg. 132, fol. 10.

153. Este alegaba que se le incendiaron cuatro molinos en Murcia y tuvo que reedificarlos: Cuentas de Antonio Sánchez de Lamadrid, sobre sus asientos de pólvora y plomo 1679-1682. AGS, CMC3, leg. 1.957 , fols. $3,3.505$ y 15 . 
la década de 1680, ante la bajada de la moneda, hubo muchos problemas con los asientos y la cobranza de las rentas reales, por lo que ante la carencia de fondos los asentistas dejaron de proveer ${ }^{154}$. Todo ello provocó el desabastecimiento ${ }^{155}$, en un momento en el que se necesitaban 25.009 quintales de pólvora para proveer todas las plazas peninsulares ante la posibilidad de que pudiera haber una guerra con Francia o Portugal ${ }^{156}$.

Tabla V. Asientos generales de pólvora en Castilla

\begin{tabular}{|c|c|c|c|c|}
\hline Asentista & Periodo & $\begin{array}{l}\text { Años de } \\
\text { Vigencia }\end{array}$ & Cantidad (en quintales) & $\begin{array}{c}\text { Precio } \\
\text { (escudos } \\
\text { de vellón) }\end{array}$ \\
\hline Antonio Graffion* & $1640-1645$ & 5 & 41.000 & 16 \\
\hline Ana Duque de Estrada* & $1650-1660$ & 10 & $\begin{array}{l}50.0000 \text { (5.000 anuales: } 2.800 \\
\text { Murcia, } 800 \text { Granada y } 1.400 \\
\text { Alcázar) }\end{array}$ & 13 \\
\hline $\begin{array}{l}\text { Marcos García Paredes y } \\
\text { Ana Duque de Estrada* }\end{array}$ & $1656-1666$ & 10 & $\begin{array}{l}5.000 \text { anuales: ( } 2.800 \text { Murcia, } \\
800 \text { Granada y } 1.400 \text { Alcázar) }\end{array}$ & 17 \\
\hline Diego Cervantes & $1657-1667$ & 10 & 4.200 anuales & 16 \\
\hline Juan Agustín Tacón* & $1671-1681$ & 10 & 2.400 anuales (solo en Murcia) & 14 \\
\hline Juan de Urrea & $1672-1676$ & 6 & 24.000 & \\
\hline $\begin{array}{l}\text { Antonio Sánchez de La- } \\
\text { madrid** }\end{array}$ & $1677-1687$ & 10 & $\begin{array}{l}40.000 \text { de pólvora y } 30.000 \text { de } \\
\text { plomo ( } 4.000 \text { anuales: } 2.500 \\
\text { Murcia, } 500 \text { Granada y } 1.000 \\
\text { Alcázar) }\end{array}$ & $\begin{array}{l}17 \text { Mur- } \\
\text { cia, } 18 \\
\text { Alcázar y } \\
\text { Granada }\end{array}$ \\
\hline Juan de Urrea & $1680-1686$ & 6 & $\begin{array}{l}4.000 \text { anuales: ( } 2500 \text { Murcia, } \\
500 \text { Granada y } 1.000 \text { Alcázar) }\end{array}$ & 18 \\
\hline
\end{tabular}

Fuentes: AGS, GA, leg. 1.894 y Libro 361; AGS, CMC3, legs. 115, 132, 742, 1.957, 2.300, 3.500 y 3.505. (Nota*: asientos que sabemos que incumplieron, ya fuera no entregando toda la cantidad o que no completaron la vigencia acordada).

154. Consulta del Consejo de Guerra, 20 de agosto 1681. AGS, GA, leg. 2.510.

155. Consultas del Consejo de Guerra, 28 de abril, 5, 7 y 12 de mayo 1681. AGS, GA, leg. 2.509. Carta del Marqués de Villafiel, Vigo, 10 de abril 1681. AGS, GA, leg. 2.533.

156. Relación de la pólvora que falta en cada plaza y presidio de España, 17 de febrero 1681. AGS, GA, leg. 2.527. 


\section{Conclusiones}

En este texto hemos intentado trabajar unos elementos poco estudiados hasta el momento, ante su aridez y la dispersión documental en demasiadas secciones que hacen necesario el continuo cruce de datos, todo ello para poder mostrar una realidad poco conocida, sin centrarnos exclusivamente en la dimensión económica, para no perder la visión social y conocer mejor sus repercusiones. El análisis de todos los asientos expuestos nos aporta algunas conclusiones. En cuanto al pan de munición, en Galicia los precios fueron más estables ante la posibilidad de importaciones marítimas, al contrario que en Extremadura, donde el aumento del ejército hizo necesaria la importación, encareciéndose el coste al tener que afrontar un transporte terrestre. En Galicia la monarquía intentó atraer a empresarios foráneos para que se hicieran cargo de la provisión, pero dicha política fue un fracaso ante las incertidumbres, fraudes e incumplimientos, cambiándose habitualmente a los asentistas, muchos de los cuales eran importantes banqueros. En Extremadura el abastecimiento estuvo monopolizado por una sola casa comercial de origen local, que al contrario que en el caso gallego pasó de trabajar de un nivel regional al nacional, siendo su provisión constante y exitosa gracias al continuo apoyo recibido por la Corona, de la que recibió premios y honores.

La pólvora en Castilla quedó convertida en un monopolio sujeto a un estanco en manos de los asentistas. Dicho sistema contribuyó a moderar los precios para el consumo militar frente a los precios de mercado, pero continuamente se debió acudir a la importación para poder atender la demanda, llegando en ocasiones a producirse un verdadero desabastecimiento. Es difícil valorar hasta qué punto el estanco de la pólvora pudo tener un efecto negativo o positivo, ya que no sabemos cuánta producción fue destinada al consumo privado, aunque queda claro que este era el verdadero beneficio de los asentistas, que es posible que solo destinaran una mínima parte de su producción a abastecer los ejércitos del rey.

Gracias a los asentistas la Corona ahorraba dinero, infraestructuras y personal, conociendo de antemano el dinero que se iba a gastar, sin tener que estar pendiente de los posibles imprevistos y de los medios que necesitaba más allá del dinero. A cambio perdía el control sobre la producción -aunque no sobre la calidad-, y cedía autoridad y otras contrapartidas a los asentistas. Unos sujetos que en muchos casos obtenían pingües beneficios económicos, y estaban muy interesados en establecer monopolios, y conseguir privilegios jurídicos y honorífi$\cos ^{157}$. Si bien la privatización de la gestión del pan no suponía un problema o una

157. Para el siglo XVIII: Torres SÁnchez, R.: «Cuando las reglas del juego cambian. Mercados y privilegio en el abastecimiento del ejército español en el siglo XVIII», Revista de Historia Moderna 20 (2002), pp. 487-512. 
pérdida de poder de la Corona, y en muchos casos supuso la supervivencia de los soldados ante la eficacia de los asentistas; la entrega de la producción y el estanco de la pólvora a manos privadas sí que supusieron la pérdida de una importante regalía. Algo que posiblemente no produjo nunca el suficiente beneficio como para que fuera rentable su cesión a manos privadas, ante los incumplimientos de los asientos y el fraude.

\section{Bibliografía}

Abreu y Bertodano, J. A.: Colección de los Tratados de Paz, alianza, garantía,... Reinado de Carlos II. Parte II, Madrid, 1751.

Andrés Ucendo, J. I. y Lanza García, R.: «Estructura y Evolución de los ingresos de la Real Hacienda de Castilla en el siglo XviI», Studia Historica. Historia Moderna 30 (2008), pp. 147-190.

Contreras Gay, J.: «Consideraciones generales sobre la defensa de la Península entre 1580 y 1640», en El Mediterráneo: hechos de relevancia histórico-militar y sus repercusiones en España, (Sevilla, 9-12 de mayo de 1995): V Jornadas Nacionales de Historia Militar. Sevilla, 1998, pp. 647-664.

Domínguez Ortiz, A.: La Sociedad Española en el siglo XVII. Vol. I, Madrid, 1963.

Eiras Roel, A.: «Las Juntas del reino de Galicia de 1642 a 1647», en Actas de las Juntas del Reino de Galicia, Vol. V: 1642-1647. Santiago de Compostela, 1995.

—-: «Las Juntas del Reino de Galicia y la política fiscal de 1655 a 1665», en Actas de las Juntas del Reino de Galicia, Vol. VII: 1655-1665. Santiago de Compostela, 1999.

—-: «Aportación documental al Mariscal Schomberg y a la invasión portuguesa de 1665 en Galicia», en Romaní Martínez, M. y Novoa Gómez, M. A. (coords.): Homenaje a José García Oro. Santiago de Compostela, 2002, pp. 119-151.

Espino López, A.: Catalunya durante el Reinado de Carlos II. Política y guerra en la frontera catalana, 1679-1697. Barcelona, 1999.

Esteban Estríngana, A.: «Administración militar y negocio de guerra en los Países Bajos católicos (siglo xviI)», en Herrero Sánchez, M. y Crespo Solana, A. (coords.): España y las 17 provincias de los Países Bajos: una revisión historiográfica (XVI-XVIII). Córdoba, 2002, vol. I, pp. 65-100.

—-: «La Ejecución del Gasto Militar y la Gestión de los Suministros. El abastecimiento de pan de munición en el ejército de Flandes durante la primera mitad del siglo XvII», en Rizzo, M. et al. (eds.): Le Forze del Principe. Recursos, Instrumentos y Limites en la Práctica del Poder Soberano en los Territorios de la Monarquia Hispánica. Murcia, 2003, vol. I, pp. 409-468.

— : «El suministro de pólvora en el ejército de Flandes. Sobre la gestión directa y delegada del aprovisionamiento militar (siglo xviI)», en García Hernán, E. y Maffi, D. (eds.): Guerra y Sociedad en la Monarquía Hispánica. Política, Estrategia y Cultura en la Europa Moderna (1500-1700). Madrid, 2006, vol. II, pp. 473-522.

GiL SANJuÁn, J.: «Industrias bélicas malague-as: la fundición de ca-ones y los molinos de pólvora en los siglos XVI y XVII», Jábega 31 (1980), pp. 21-36. 
Goodman, D.: El poderío naval española. Historia de la Armada española del siglo XVII. Barcelona, 2001.

Hale, J. R.: Guerra y sociedad en la Europa del Renacimiento, 1450-1620. Madrid, 1990, pp. 204-205.

Henríquez de Villegas, D.: Levas de gente de guerra: su empleo en todas las facciones militares... Madrid, 1647.

Jiménez Estrella, A.: «Asentistas militares y fraude en torno al abastecimiento de pólvora en el reino de Granada (siglo Xvi)», Investigaciones históricas: Época moderna y contemporánea 30 (2010), pp. 11-29.

MAfFi, D.: «L'Amministrazione della Finanza Militare nella Lombardia Spagnola: I Veedores e I Contadores dell'Esercito (1536-1700)», Storia Economica 5 (2002), pp. 54-106.

Parker, G.: El ejército de Flandes y el Camino Español, 1567-1659. Madrid, 1991.

Rodríguez Hernández, A. J.: La ciudad y la guarnición de Ceuta (1640-1700). Ejército, fidelidad e integración de una ciudad portuguesa en la Monarquía Hispánica. Ceuta, 2011, pp. 110-115.

- : «Al servicio del rey. Reclutamiento y transporte de soldados italianos a España para luchar en la Guerra contra Portugal (1640-1668)», Guerra e pace in età moderna. Annali di storia militare europea 4 (2012), pp. 229-275.

- : «Las Cortes de Castilla y la leva para los Presidios: La gestión de la primera recluta obligatoria de los Austrias», en Pérez Álvarez, M. J., Rubio Pérez, L. M., Martín García, A. (eds.): Campo y campesinos en la España Moderna. Culturas políticas en el mundo bispano. León, 2012, pp. 1731-1744.

- : «Los primeros ejércitos peninsulares y su influencia en la formación del Estado Moderno durante el siglo XVII», en González Enciso, A. (ed.): Un Estado Militar. España, 1650-1820. Madrid, 2012, pp. 19-64.

Ruiz Ibáñez, J. J: Las dos caras de Jano. Monarquía, ciudad e individuo Murcia, 15881648. Murcia, 1995.

SaAvedra Vázquez, M. C.: «La formación de armadas y sus efectos a nivel territorial: el ejemplo de Galicia 1580-1640», Cuadernos de Historia Moderna. Anejos V (2006), pp. 55-76.

Sala y Abarca, F. V.: Después de Dios la Primera obligación y glosa de órdenes militares. Nápoles, 1681.

SÁNchez Gómez, J.: «Abastecimiento y desabastecimiento de pólvora en España en el siglo XvI», Studia Histórica. Historia Moderna 3 (1985), pp. 55-62.

SANZ Ayán, C.: «La problemática del abastecimiento de los Ejércitos de Extremadura y Cataluña durante 1652», en Temas de historia militar: $2^{\circ}$ Congreso de Historia Militar. Zaragoza, 1988, vol. 2, pp. 221-236.

- : Los Banqueros de Carlos II. Valladolid, 1989.

STORRs, C.: «The Army of Lombardy and the Resilience of Spanish Power in Italy in the Reign of Carlos II (1665-1700) Part Two», War in History 5 (1998), pp. 1-22. http://dx.doi.org/10.1177/096834459800500101 http://dx.doi.org/10.1191/096834498671125700 
TAllet, F.: War and Society in Early Modern Europe 1495-1715. Routledge, 1992. http://dx.doi.org/10.4324/9780203411247

Thompson, I. A. A.: «The purchase of nobility in Castile, 1552-1700», Journal of European Economic History 8 (1979), pp. 313-360.

- Guerra y decadencia: gobierno y administración en la España de los Austrias, 15601620. Barcelona, 1981.

—-: «Aspectos de la organización naval y militar durante el ministerio de Olivares», en Elliott, J. y García SAnz, A. (coords.): La España del Conde Duque de Olivares. Valladolid, 1990, pp. 249-274.

Tilly, C.: Coercion, Capital and European States: AD 990-1992. Cambridge, 1990.

Torres SÁnchez, R.: «Cuando las reglas del juego cambian. Mercados y privilegio en el abastecimiento del ejército español en el siglo xviII», Revista de Historia Moderna 20 (2002), pp. 487-512.

Van Creveld, M.: Supplying War. Logistics from Wallenstein to Patton. Cambridge, 1977.

Van Nimwegen, O.: The Dutch Army and the Military Revolutions 1588-1688. Boydell, 2010.

White, L.: War and Government in a Castilian province: Extremadura, 1640-1668. Tesis doctoral inédita, Universidad de East Anglia, 1985. 